WSRC-TR-2003-00533

Rev. 0

\title{
Porous Medium Analysis of Interstitial Liquid Removal from Tank 41 and Tank 3 (U)
}

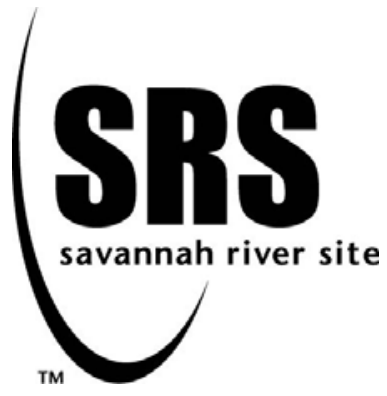


This document was prepared in conjunction with work accomplished under Contract No. DE-AC09-96SR18500 with the U. S. Department of Energy.

\section{DISCLAIMER}

This report was prepared as an account of work sponsored by an agency of the United States Government. Neither the United States Government nor any agency thereof, nor any of their employees, makes any warranty, express or implied, or assumes any legal liability or responsibility for the accuracy, completeness, or usefulness of any information, apparatus, product or process disclosed, or represents that its use would not infringe privately owned rights. Reference herein to any specific commercial product, process or service by trade name, trademark, manufacturer, or otherwise does not necessarily constitute or imply its endorsement, recommendation, or favoring by the United States Government or any agency thereof. The views and opinions of authors expressed herein do not necessarily state or reflect those of the United States Government or any agency thereof.

This report has been reproduced directly from the best available copy.

Available for sale to the public, in paper, from: U.S. Department of Commerce, National Technical Information Service, 5285 Port Royal Road, Springfield, VA 22161, phone: (800) 553-6847, fax: (703) 605-6900

email: orders@ntis.fedworld.gov

online ordering: http://www.ntis.gov/help/index.asp

Available electronically at http://www.osti.gov/bridge

Available for a processing fee to U.S. Department of Energy and its contractors, in paper, from: U.S. Department of Energy, Office of Scientific and Technical Information, P.O. Box 62, Oak Ridge, TN 37831-0062,

phone: (865)576-8401,

fax: (865)576-5728

email: $\underline{\text { reports@ adonis.osti.gov }}$ 
WSRC-TR-2003-00533

Rev. 0

\section{Porous Medium Analysis of Interstitial Liquid Removal from Tank 41 and Tank 3 (U)}

G. P. Flach

Westinghouse Savannah River Company

Savannah River Site

Aiken SC 29808

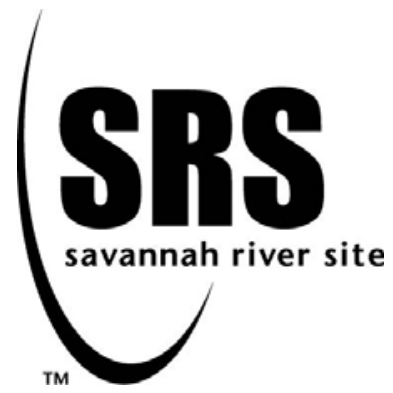


This page was intentionally left blank 


\section{Executive Summary}

During Tank 41 interstitial liquid removal in fall 2002 and early 2003, analytical analyses of capillary liquid retention and fluid flow in porous saltcake were performed to guide waste processing under the Low Curie Salt program. Tank drainage was completed in June 2003 with the interstitial level at about 68 in. In late June and early July, flush water was added to dissolve hard salt for later liquid retrieval. Data from these subsequent operations has been used to validate the earlier analytical models and assess model uncertainty. Data comparisons suggest the analytical drain model performs well when empirical data are available to calibrate the model. Subsequent model forecasts can be expected to be reasonably accurate, provided the pumping rate is steady.

A numerical model of porous medium flow was developed for Tank 41 using a modified version of the finite-element FACT code. The numerical modeling approach can readily accommodate differences in geometry and fluid properties between tanks. Intrinsic permeability for Tank 41 was estimated with the numerical model by comparing actual to simulated well liquid level in response to known pumping rates. Intrinsic permeability is a physical property of a porous media and not dependent on the interstitial fluid. Based on numerical modeling, the average intrinsic permeability of the saltcake in Tanks 41 and 3 appears to lie in the range of 25 to 50 Darcy. A best-estimate is 37 Darcy.

A similar finite-element model was developed for Tank 3, and used to assess the benefit of installing an additional salt well. Little benefit is predicted for a 45 day operational window. Drainage data for the lower 160 in. of saltcake, suggest that the saltcake in Tanks 41 and 3 share the same porous medium properties. Saltcakes of similar chemical composition are likely to have similar physical properties. Thus, the prospect of achieving reasonably good drainage forecasts for other salt tanks looks promising. However, the presence of unknown/undefined macroscopic voids in the saltcake would lead to significant prediction errors, as was observed for the upper 40 in. in Tank 3. Characterization of such supernate-filled pockets would be highly beneficial toward accurately estimating drain volumes and progress. Characterization and detection of such supernate-filled pockets could be identified using Cone Penetration Testing (CPT) technology and gamma monitoring of tank interior from a monitoring well installed beneath a riser. Cost benefit and risk analysis can be used to determine the data needed to characterize a tank prior to draining. 


\section{Contents}

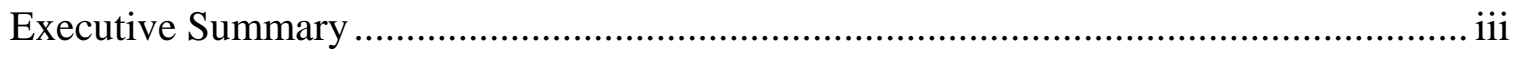

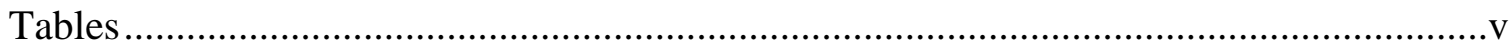

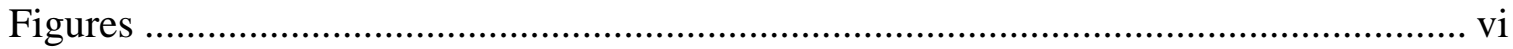

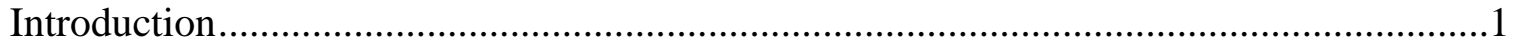

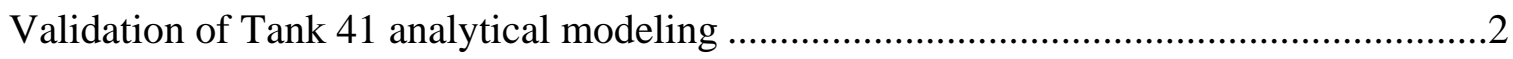

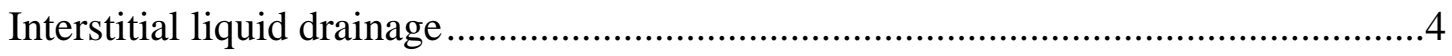

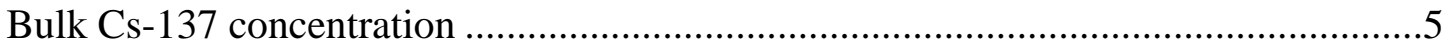

Dissolved salt solution concentration ..................................................................6

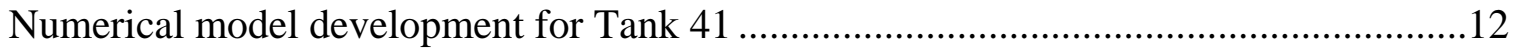

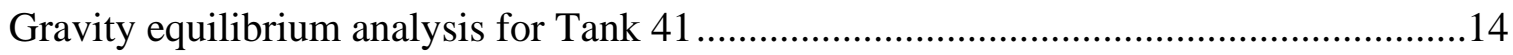

Average intrinsic permeability of saltcake in Tank 41 ...............................................15

Forecasts of Tank 3 interstitial liquid removal ..........................................................19

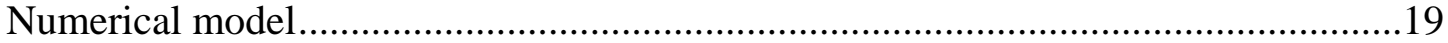

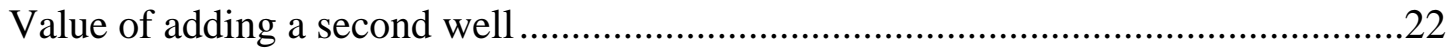

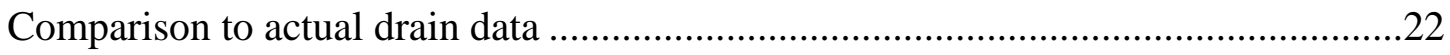

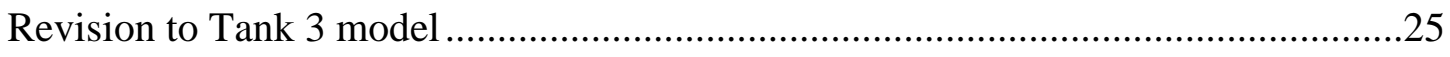

Comparison to physical property measurements on saltcake samples ............................29

Characterization and model development needs .....................................................29

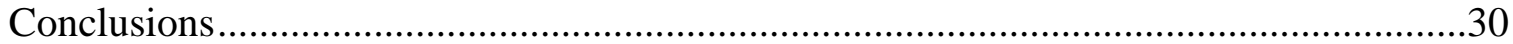

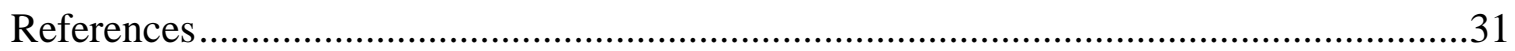

Appendix A - Tank 41 dissolution and refill mixing calculations.................................33

Appendix B - Estimation of Tank 41 and Tank 3 interstitial fluid properties as a function

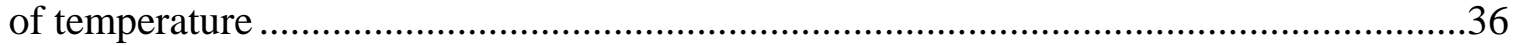




\section{Tables}

Table 1 Best-estimates of saltcake porous medium physical properties from Flach (2003b).

Table 2 Assumed saltcake and dissolution chemistry parameters for Tank 41 flush water addition in July 2003.

Table 3 Estimate of Tank 41 supernate concentration in July under a no mixing scenario

Table $4 \quad$ Estimate of Tank 41 supernate concentration in July under a complete mixing above 103 in. scenario

Table 5 Estimate of Tank 41 supernate concentration in July under a partial mixing above 103 in. scenario

Table 6 Estimated bulk saltcake concentration for drained saltcake, and saltcake refilled with dissolved salt solution

Table $7 \quad$ Actual volume pumped from Tank 41 compared to analytical and numerical estimates of the volume change for the same liquid level change

Table $8 \quad$ Viscosity and hydraulic conductivity estimates for Tanks 3 and 41 at 20 and $50{ }^{\circ} \mathrm{C}$

Table 9 Estimated volume fraction of supernate in pools in upper saltcake within Tank 3 


\section{Figures}

Figure 1 Well liquid level in Tank 41 during interstitial liquid removal operations from 9/8/02 through 12/9/02 ………………….......................

Figure 2 Capillary water retention curves for common soils (surrogate porous media for saltcake)

Figure 3 Predicted and actual drainage progress for Tank 41 from March through June 2003.

Figure 4 Comparison of saltcake sample and gamma probe measurement to water retention model predictions for Tank 41

Figure 5 Schematic diagrams of a) no mixing, b) partial mixing and c) complete mixing scenarios; concentrations in Ci/gal Cs-137.

Figure 6 Forecast gamma profile under various mixing scenarios

Figure $7 \quad$ Finite-element grid and material property specification for Tank 41 porous medium flow simulation; blue shading corresponds to saltcake, yellow/tan to air and/or supernate filled volume

Figure 8 Finite-element grid and material property specification in the vicinity of the salt well beneath the Tank $41 \mathrm{C} 1$ riser

Figure 9 Actual and simulated liquid levels in Tank 41 for a hydraulic conductivity of 75 in/d

Figure 10 Actual and simulated volume changes in Tank 41 for a hydraulic conductivity of $75 \mathrm{in} / \mathrm{d}$

Figure 11 Actual and simulated liquid levels in Tank 41 for a hydraulic conductivity of $150 \mathrm{in} / \mathrm{d}$

Figure 12 Actual and simulated volume changes in Tank 41 for a hydraulic conductivity of $150 \mathrm{in} / \mathrm{d}$.

Figure 13 Snapshot of simulated liquid level, hydraulic head contours (5 in. intervals), and liquid content in Tank 41 at an elapsed time of 3.7 days for a hydraulic conductivity of $75 \mathrm{in} / \mathrm{d}$.

Figure 14 Finite-element grid for Tank 3 porous medium flow simulation; the center column is a hypothetical composite of 12 physical support columns

Figure 15 Finite-element mesh detail around Tank 3 salt well

Figure 16 Simulated drainage of Tank 3 for one and two salt wells using low and high permeability estimates derived from Tank 41 (25 and 50 Darcy)

Figure 17 Anticipated interstitial liquid removal progress for Tank 3; reproduced from CBU-SPT-2003-00174. 


\section{Figures (continued)}

Figure 18 Day 4 morning report for Tank 3 interstitial liquid removal; reproduced from CBU-SPT-2003-00174........

Figure 19 Hypothetical rings of $100 \%$ porosity material representing the composite effect of 53\% macroscopic voids in the upper Tank 3

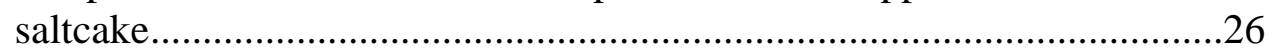

Figure 20 Pumping rate and interstitial liquid volume removed for Tank 3..............27

Figure 21 Actual and predicted well levels during Tank 3 drainage .........................28 
This page intentionally left blank 


\section{Introduction}

During Tank 41 interstitial liquid removal in fall 2002 and early 2003, analytical analyses of capillary liquid retention and fluid flow in porous saltcake were performed to guide waste processing under the Low Curie Salt program (Flach 2003a, b). Tank drainage was completed in June 2003 with the interstitial level at about 68 in. In late June and early July, flush water was added to dissolve hard salt for later liquid retrieval. Information from these subsequent operations can be used to validate (or invalidate) the earlier analytical models and assess model uncertainty. To this end, model predictions and data are compared in this report in three areas: interstitial liquid drainage rates, bulk Cs-137 concentration, and concentration of Cs-137 in the dissolved salt solution.

The prediction of drain rates during subsequent Tank 41 interstitial liquid removal operations was derived through empirical model calibration to the early drainage data. The empirical nature of the analytical model is rooted in an inability to capture the threedimensional geometry of the tank and corresponding flow field, and transient effects. This limitation can be overcome by taking a numerical modeling approach. A finiteelement porous medium flow code named FACT (Hamm and Aleman 2000) was used to develop a three-dimensional transient model of interstitial liquid flow in Tank 41. Intrinsic permeability for Tank 41 was then estimated with the numerical model by comparing actual to simulated well liquid level in response to measured pumping rates. Intrinsic permeability is a physical property of a porous media and not dependent on the interstitial fluid. Intrinsic permeability coupled with fluid density and viscosity define the hydraulic conductivity of a porous media. Interstitial fluid flow rate is proportional to hydraulic conductivity and hydraulic head gradient.

Intrinsic permeability is controlled by the physical structure of the porous media. Differences in saltcake physical attributes, such as particle/crystal size distribution and morphology, typically result in permeability differences. Saltcakes with similar chemical composition and tank operating history may be physically similar. With this assumption, blind forecasts of drainage rates for other tanks can be made using the numerical model, which rigorously accounts for differences in fluid properties and tank geometry compared to Tank 41. Such predictions were made for Tank 3 (Brass 2003), the next tank being drained of interstitial liquid, as described in the present report. The assumption that SRS saltcakes have a similar intrinsic permeability as Tank 41 is a critical hypothesis that has not been validated. 


\section{Validation of Tank 41 analytical modeling}

Model calibration to the drainage data shown in Figure 1 lead to predictive models of well drawdown relative to tank average interstitial liquid level, estimated drain times and a range of plausible saltcake physical properties, as reported in Flach (2003a). Consideration of additional information about saltcakes at both the Savannah River and Hanford sites narrowed the range to the best-estimates given in Table 1 where the capillary retention curves for Sandy Loam and Loam soil are shown in Figure 2 among other potential soil surrogates (Flach 2003b).

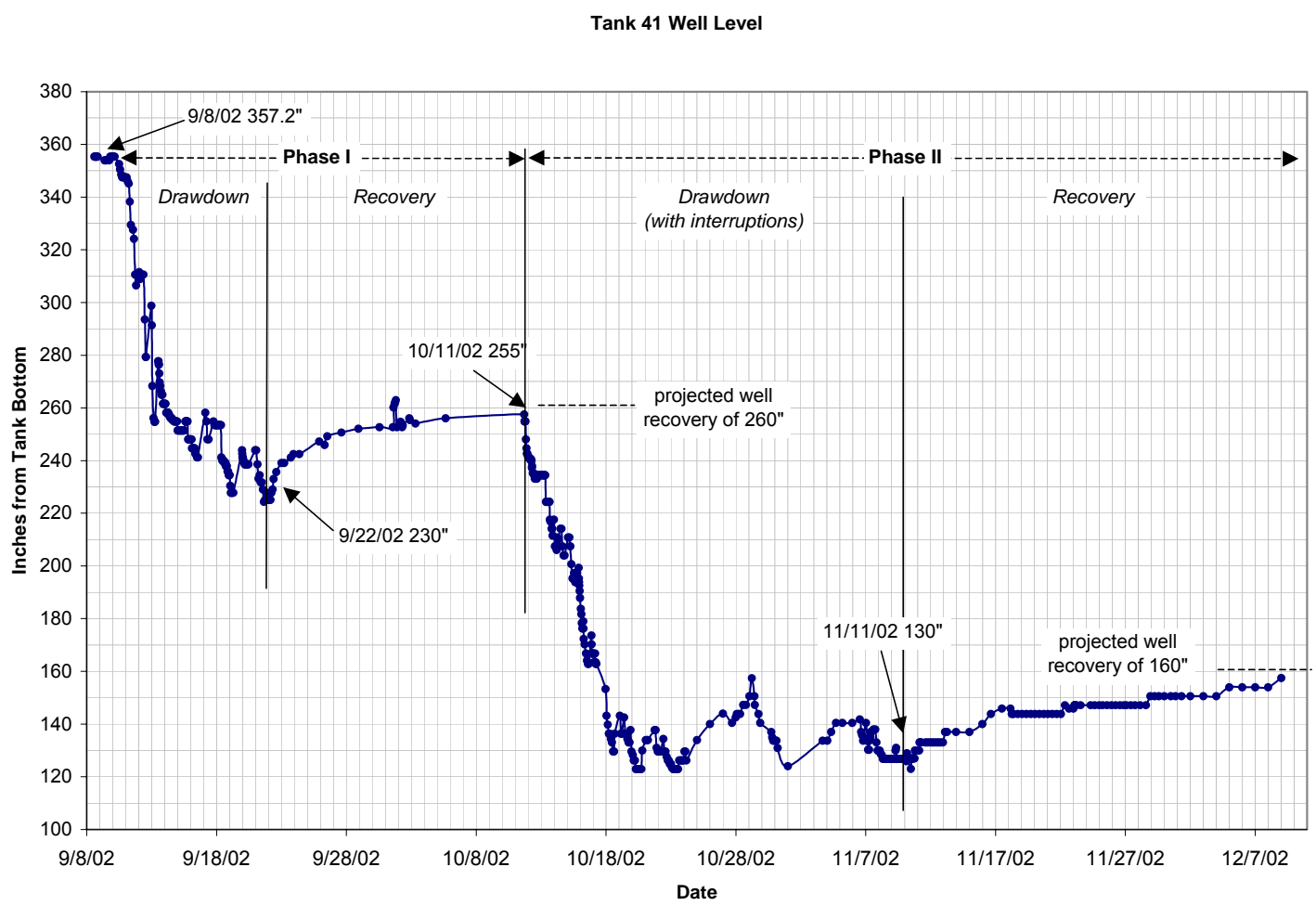

Figure 1 Well liquid level in Tank 41 during interstitial liquid removal operations from $9 / 8 / 02$ through 12/9/02. 
Table 1 Best-estimates of saltcake porous medium physical properties from Flach (2003b).
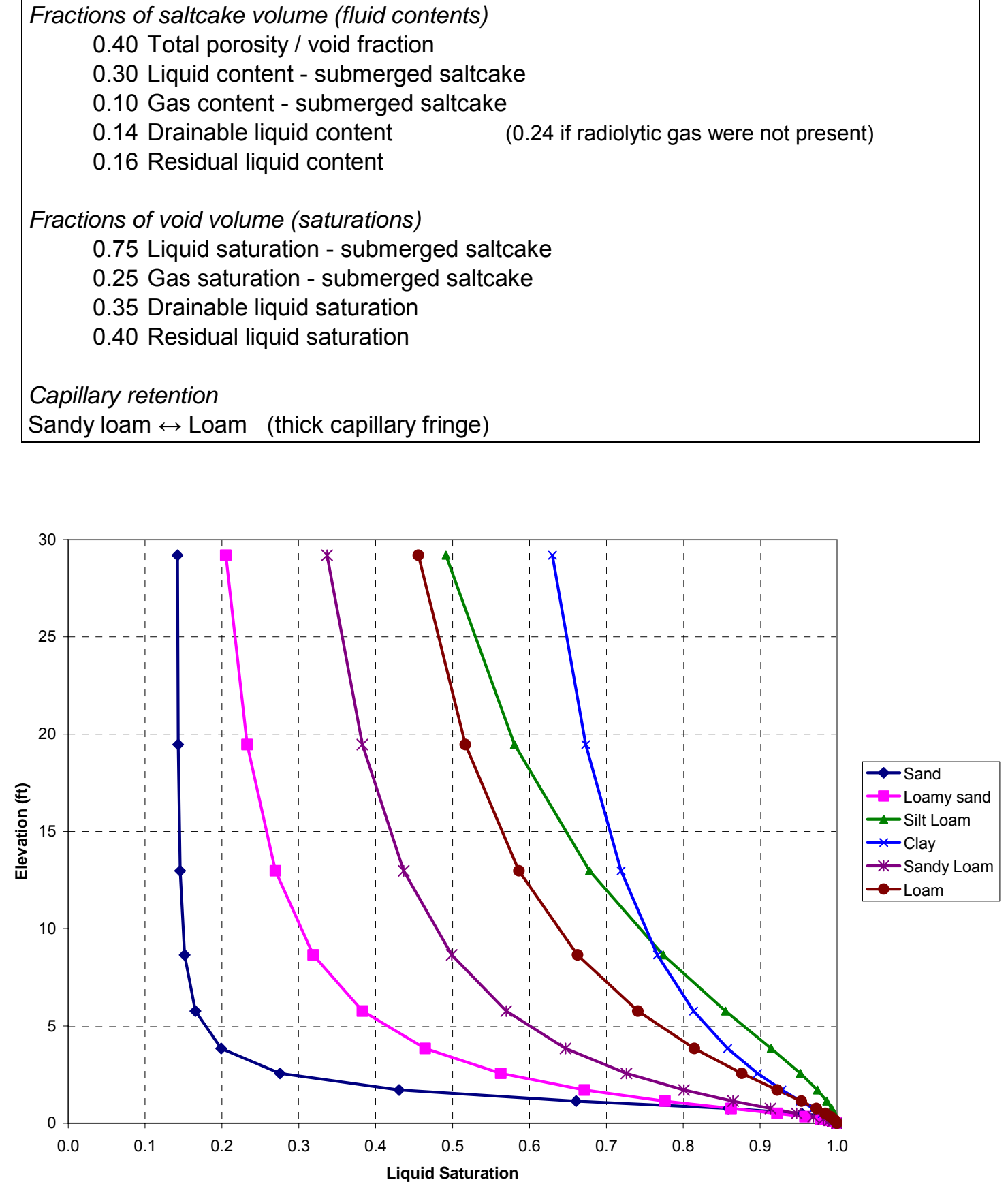

Figure 2 Capillary water retention curves for common soils (surrogate porous media for saltcake). 


\section{Interstitial liquid drainage}

The prior study included an approximate analytical expression for estimating the time required to remove a specified volume of interstitial fluid, or equivalently to lower the average interstitial level from a specified initial height to a specified final elevation (cf. Flach 2003a, equation (39)). The drain time expression was based on an analytical flow model that had been calibrated to the well recovery event during downtime between 9/22/02 and 10/11/02 (cf. Flach 2003a, equation (32)). Figure 3 compares predicted interstitial liquid volume left to be drained, "gallons-to-go", as a function of pump operating time. The agreement is excellent through nearly 300 hours. After that intermittent pump operation cause poorer agreement, although still good except near the end. The analytical solution assumes pseudo steady-state, slow transient conditions, which was not the case when the sump pump operated intermittently. The comparison indicates that the analytical expression, once calibrated to initial drainage data, can be expected to produce accurate estimates of subsequent drain rates while pump operation is reasonably continuous.

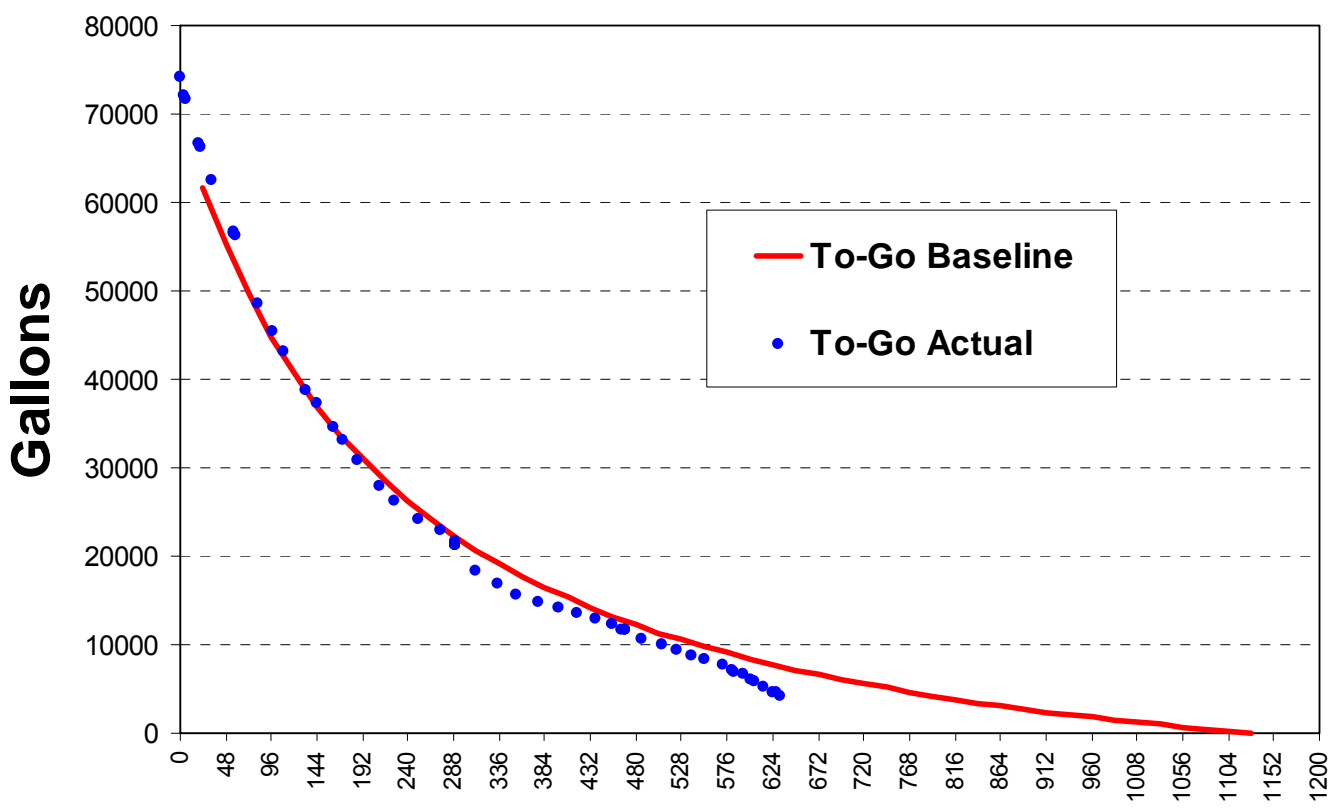

\section{Pump Operating Hours}

Figure 3 Predicted and actual drainage progress for Tank 41 from March through June 2003. 


\section{Bulk Cs-137 concentration}

The prior study also presented a technique for estimating the amount of interstitial liquid retained in saltcake after drainage. Assuming nearly all of the Cs-137 is in a soluble form, bulk saltcake concentration can be estimated from estimates of residual liquid fraction and Cs-137 concentration in the liquid phase.

For an estimated liquid concentration of $2.5 \mathrm{Ci} / \mathrm{gal}$ in Tank 41 (Drumm and Hopkins 2003), Figure 4 depicts the resulting estimated vertical profile of bulk Cs-137 concentration (activity per saltcake volume) for two periods corresponding to liquid levels of approximately $171 \mathrm{in.}$ and $65 \mathrm{in.}$ For comparison, laboratory measurements from drained saltcake samples and gamma activity measurements from the tank annulus are also shown (Martino and Nichols 2003; Moore 2003a). The gamma probe and sample results agree closely where the two data types overlap, and constitute a cross-validation of the two measurements.

With respect to the porous medium model, the overall trend and the relative effect of lowering the tank level from 171 in. to 65 in. are consistent with the gamma probe results. In the interval of 65 in. to 171 in., the gamma results indicate a higher initial liquid content than predicted by the porous medium model. The residual amounts after drainage are about the same however. Because the model assumes a homogeneous saltcake, the predictions based on water retention vary much more smoothly than the gamma probe results, which indicate that the saltcake is not homogeneous. Other information supports this conclusion. Hard layers at 260 in. and 200 in. were observed during salt well mining (Romanowski 2003). An interesting example of heterogeneity is the spike in the Mar03 gamma results at 130 in., that subsequently disappears. The saltcake is probably much more porous around that elevation resulting in a significantly higher initial liquid content, and lower residual content as evidenced by the low spike in the Jun03 curve at 130 in. Below 65 in. the gamma results increase steadily with depth while the water retention model predicts a flat profile. The reason for the higher gamma results is not known.

The laboratory sample and gamma probe measurements of Cs-137 activity in drained saltcake indicate the best-estimate residual liquid content defined in Table 1 is approximately valid for Tank 41. 


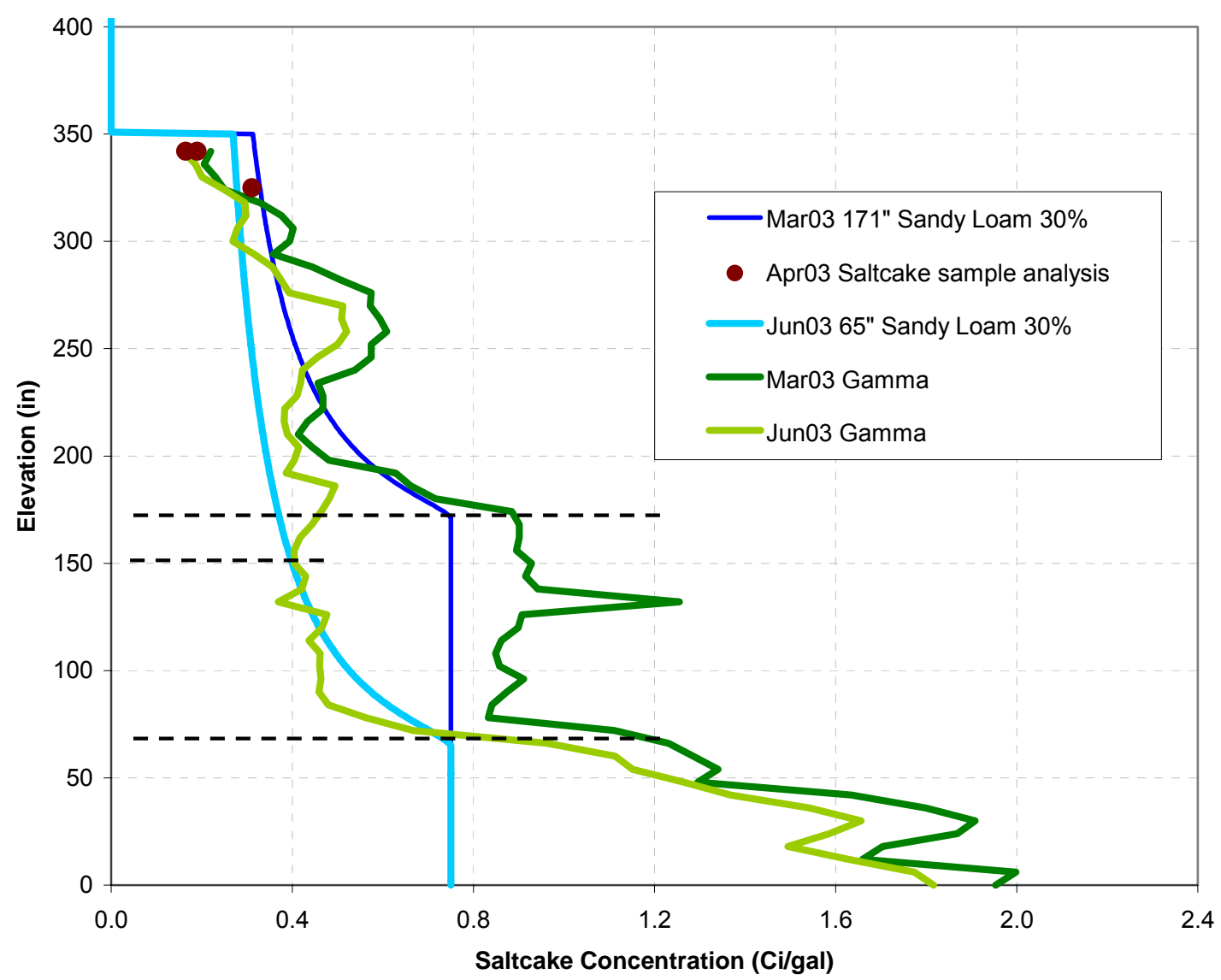

Figure 4 Comparison of saltcake sample and gamma probe measurement to water retention model predictions for Tank 41 .

\section{Dissolved salt solution concentration}

When flush water was added to Tank 41 in late June and early July 2003, some hard salt was dissolved creating a saturated solution. This dissolved salt solution partially mixed with residual interstitial liquid in the saltcake, both in the region dissolved and surrounding volume. The degree of mixing between interstitial and dissolved salt solutions is not known, but is bounded by the endpoints of complete mixing and no mixing. In this section, bounding estimates of liquid concentrations in Tank 41 are calculated using the best-estimate porous medium properties listed in Table 1.

In performing the analysis, a distinction is made between interstitial liquid residing in pore spaces by definition, and "free" liquid residing in large pools outside the saltcake proper. Pools of free liquid formed after cavities in the saltcake were created through dissolution, and the tank liquid level was restored to approximately $350 \mathrm{in}$. Except in the case of complete fluid mixing, the two bodies of liquid are assumed to take on different 
Cs-137 concentrations. Dip samples of the "free" liquid have been taken twice since early July.

The gas content in Tank 41 prior to drainage was estimated previously to be 10\% (Table 1). Immediately after tank draining and refilling with flush water to create dissolved salt solution, the gas content would presumably be near zero. A period of several months or years would be required for radiolysis to return the gas content to the original $10 \%$ (Hester 2003). For the few months following flush water addition, the gas content is assumed to be near zero. With this assumption, refilled saltcake has a liquid content of $40 \%$ compared to $30 \%$ before drainage. Other inputs to the analysis are summarized in Table 2. The drainable and residual liquid contents differ slightly from Table 1, reflecting model calibration to additional drainage data acquired after Table 1 was developed.

A lower bound on Cs-137 concentration in the free liquid can be estimated by assuming no mixing of the dissolved salt solution with interstitial liquid in surrounding saltcake. In this case, the free liquid is comprised solely of dissolved salt solution. This scenario is equivalent to removing a sample of drained saltcake from the tank and dissolving it in isolation. It is also equivalent to dissolving the entire tank contents in a hypothetical separate tank, 3-4 times larger to accommodate the increased volume of salt solution. As shown in Table 3, the low bound is $0.11 \mathrm{Ci} /$ gal. A high estimate can be derived under the assumption that liquid in the tank becomes completely mixed in the refilled portion of saltcake, effectively that volume above $103 \mathrm{in}$. corresponding to a liquid level of $68 \mathrm{in}$. plus an assumed 35 in. capillary fringe. Also, the $354 \mathrm{kgal}$. of salt solution predicted to have been created (Table 4) would produce a liquid level higher than the 347 in. observed at the conclusion of flush water addition, using the properties in Table 2 . If the volume of salt solution created is calculated from the liquid level change, the result is $300 \mathrm{kgal}$. Using this lower volume also leads to a higher estimate of Cs-137 concentration in liquid. With these two assumptions, a high estimate for the free liquid is $0.68 \mathrm{Ci} /$ gal (Table 4; Appendix A).

The measured concentration of Cs-137 in dip samples of free liquid taken soon after flush water addition was completed was about $0.38 \mathrm{Ci} /$ gal (Martino et al. 2003), which lies in between the preceding two estimates and suggests a partial mixing of dissolved salt solution with interstitial liquid. If the free liquid concentration is set to the measured value of $0.38 \mathrm{Ci} /$ gal for a third scenario more closely resembling actual conditions, the interstitial liquid concentration becomes $0.80 \mathrm{Ci} /$ gal (Table 5). Figure 5 provides schematic diagrams of the three scenarios and the corresponding free and interstitial liquid concentrations. Calculation details for all three scenarios are provided in Appendix A, where the volume of salt solution created is based on the liquid level change rather than salt solution / feed ratio in Table 2. 
The concentrations of Cs-137 in the free and interstitial liquids are expected to gradually equilibrate over time due to diffusion and natural convection flows. In the shorter term, the free liquid concentration should approach $0.68 \mathrm{Ci} /$ gal, the average concentration above 103 in. (Figure 5). Over a longer period, the free liquid concentration should reach $1.06 \mathrm{Ci} / \mathrm{gal}$, the average for the entire liquid inventory. Additional samples of the free liquid were taken in early September, two months after flush water addition (Martino 2003). The average Cs-137 concentration in these samples was $0.61 \mathrm{Ci} / \mathrm{gal}$, which indicates that Cs-137 is in fact mixing between the free and interstitial liquid volumes.

Complete mixing, including the region below 103 in., produces the highest free liquid concentration, nearly 1.1 Ci/gal as indicated in Figure 5. Thus $1.1 \mathrm{Ci} /$ gal constitutes an upper bound on free liquid concentration immediately after flush water addition. The lower $(0.11 \mathrm{Ci} / \mathrm{gal})$ and upper $(1.1 \mathrm{Ci} / \mathrm{gal})$ bounds on Tank 41 free liquid concentration span an order of magnitude. Uncertainty in the actual mixing conditions in Tank 41 precludes making any statement about the validity of the assumed porous medium parameters from Table 1, and would likely be the largest source of uncertainty in forecasts of free and interstitial liquid concentrations following dissolution for other tanks.

As an interesting side note, gamma scans from the annulus before and after flush water addition showed essentially no change in the bulk saltcake concentration (Moore 2003b). The gamma probe is assumed to have monitored only saltcake and not be influenced by supernate pools which lie away from the tank wall. Table 6 summarizes the bulk saltcake concentrations predicted for drained saltcake and saltcake refilled with dissolved salt solution under different mixing scenarios, and the information is plotted in Figure 6. Note that the bulk saltcake is unchanged in the drained and partially mixed scenarios, consistent with gamma probe observations.

Table 2 Assumed saltcake and dissolution chemistry parameters for Tank 41 flush water addition in July 2003.

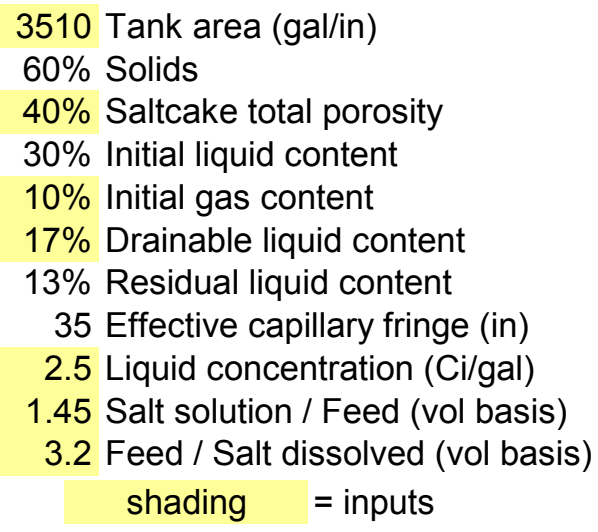


Table 3 Estimate of Tank 41 Cs-137 liquid concentrations in July under a no mixing scenario.

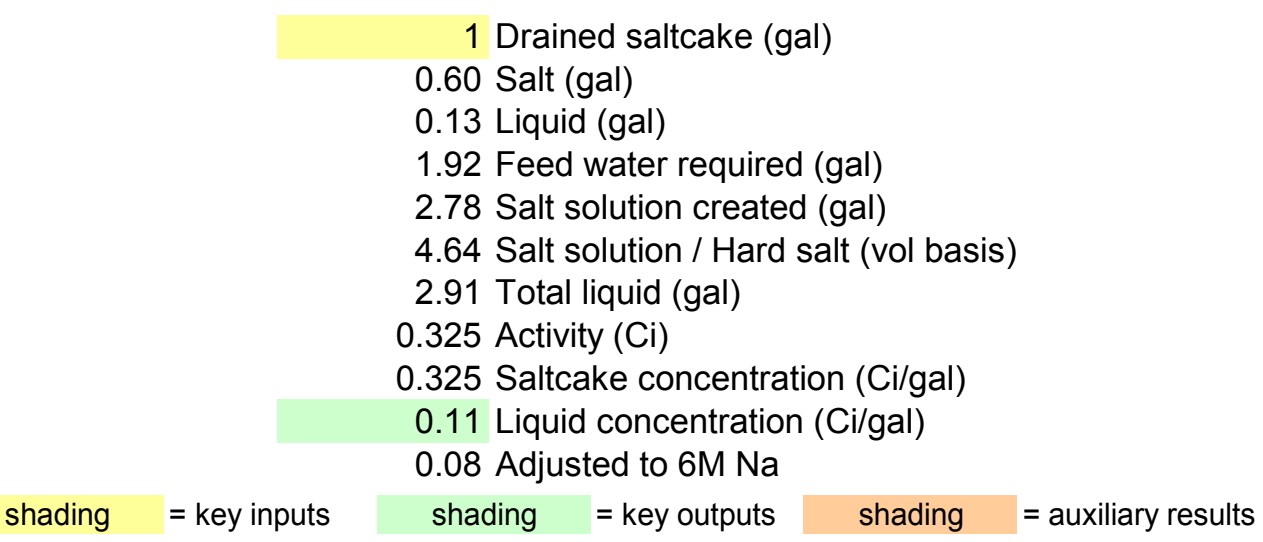

Table 4 Estimate of Tank 41 Cs-137 liquid concentrations in July under a complete mixing above 103 in. scenario.

244,000 Feed water (gal)

353,800 Salt solution (gal)

76,250 Salt dissolved (gal)

101 Liquid created (in)

22 Salt dissolved (in)

36 Saltcake dissolved (in)

1.06 Average liquid conc (Ci/gal)

0.68 Average liquid conc in REFILLED SALTCAKE AND FREE LIQUID (Ci/gal)

0.68 Assumed concentration of FREE LIQUID (Ci/gal)

0.68 Average liquid concentration in REFILLED SALTCAKE (Ci/gal)

0.38 Sample (Ci/gal)

shading = key inputs shading = key outputs shading = auxiliary results

Table 5 Estimate of Tank 41 Cs-137 liquid concentrations in July under a partial mixing above 103 in. scenario.

244,000 Feed water (gal)

353,800 Salt solution (gal)

76,250 Salt dissolved (gal)

101 Liquid created (in)

22 Salt dissolved (in)

36 Saltcake dissolved (in)

1.06 Average liquid conc (Ci/gal)

0.68 Average liquid conc in REFILLED SALTCAKE AND FREE LIQUID (Ci/gal)

0.38 Assumed concentration of FREE LIQUID (Ci/gal)

0.80 Average liquid concentration in REFILLED SALTCAKE (Ci/gal)

0.38 Sample (Ci/gal)

shading = key inputs shading = key outputs shading = auxiliary results 
a) No mixing scenario

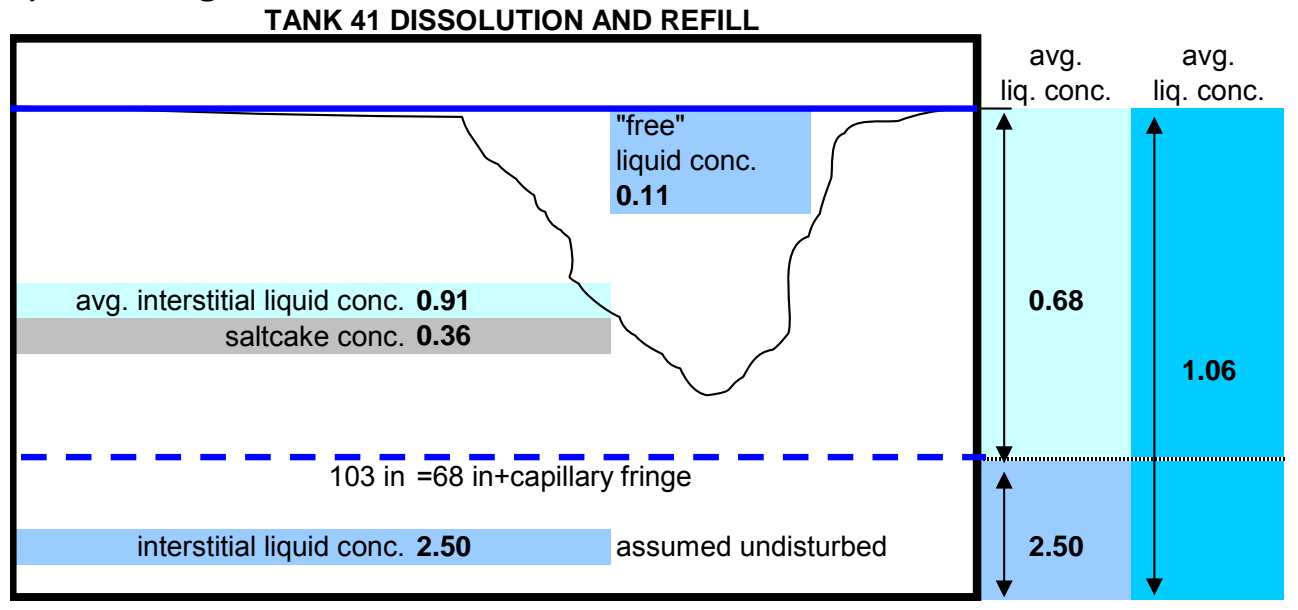

b) Partial mixing above 103 in. scenario TANK 41 DISSOLUTION AND REFILL

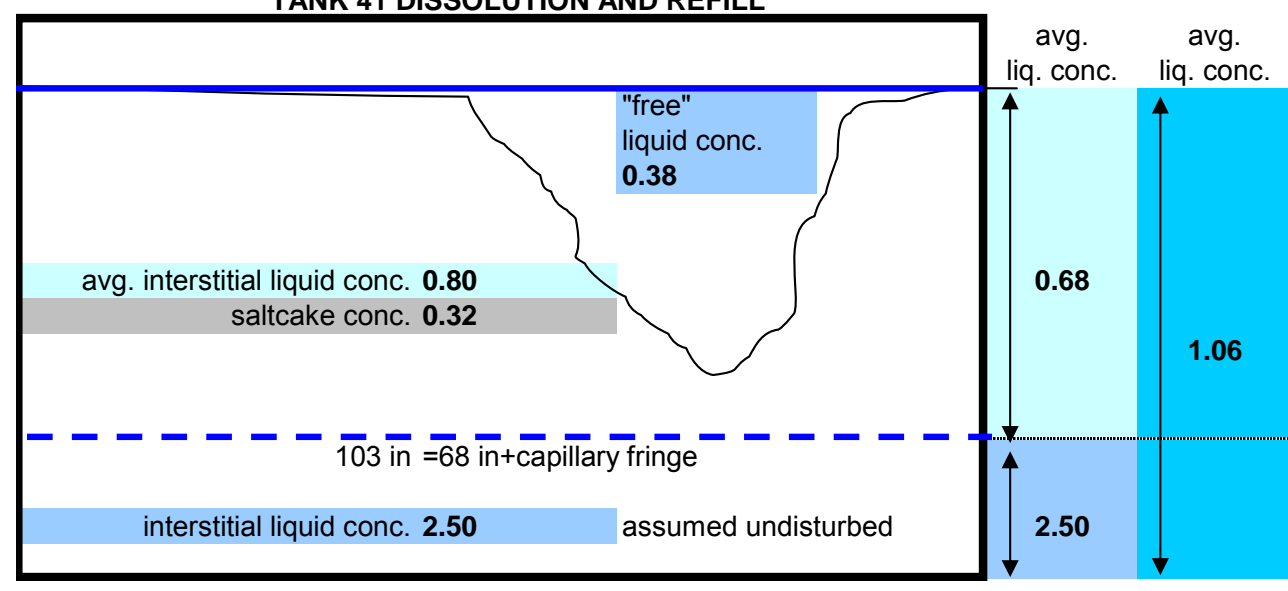

c) Complete mixing above 103 in. scenario

TANK 41 DISSOLUTION AND REFILL

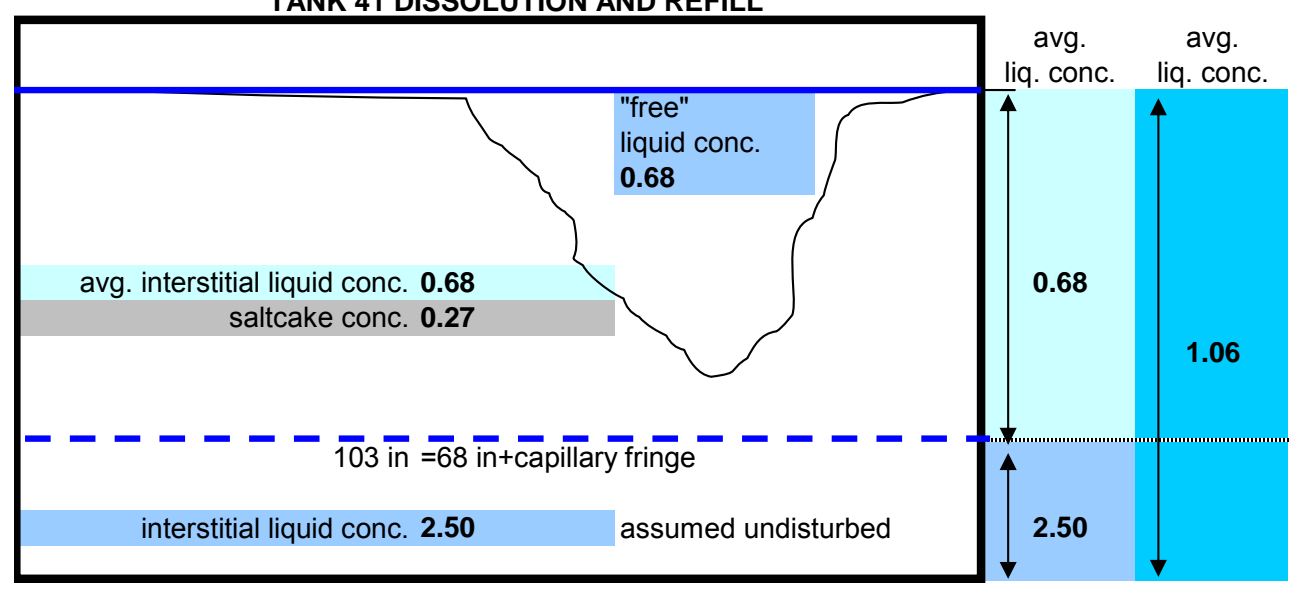

Figure 5 Schematic diagrams of a) no mixing, b) partial mixing and c) complete mixing scenarios; concentrations in Ci/gal Cs-137. 
Table 6 Estimated bulk saltcake concentration for drained saltcake, and saltcake refilled with dissolved salt solution.

\begin{tabular}{|ccccc|}
\hline Elev (in.) & Drained & \multicolumn{3}{c|}{ Refilled Saltcake } \\
& & Complete & Partial \\
& & No mixing & mixing & mixing \\
\hline 347 & 0.33 & 0.36 & 0.27 & 0.32 \\
103 & 0.33 & 0.36 & 0.27 & 0.32 \\
103 & 0.75 & 0.75 & 0.75 & 0.75 \\
0 & 0.75 & 0.75 & 0.75 & 0.75 \\
\hline
\end{tabular}

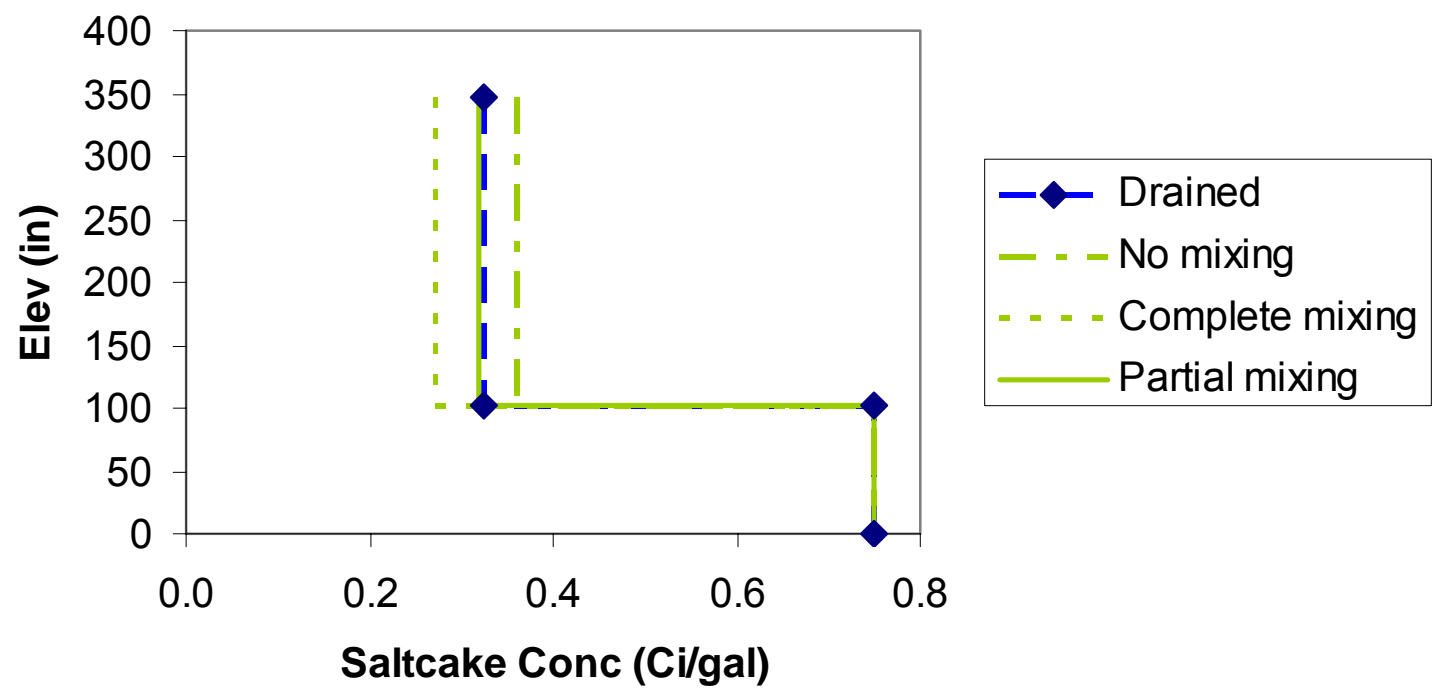

Figure $6 \quad$ Forecast gamma profile under various mixing scenarios. 


\section{Numerical model development for Tank 41}

The prediction of drain rates during the latter half of Tank 41 interstitial liquid removal operations was derived through empirical model calibration to initial drainage data. The empirical nature of the analytical model is rooted in an inability to explicitly capture the three-dimensional geometry of the tank and corresponding flow field, and transient effects. To overcome this limitation, a numerical modeling approach was adopted to support Tank 3 interstitial liquid removal operations. A finite-element model was first developed for Tank 41 in order to deduce the average intrinsic permeability of saltcake from drainage data. Intrinsic permeability estimates from Tank 41 were then used in a finite-element model of Tank 3 to forecast interstitial liquid removal rates for that tank.

Figure 7 illustrates the finite-element mesh chosen for Tank 41 simulations. Tank 41 is about $85 \mathrm{ft}$ in diameter and nearly $34 \mathrm{ft}$ high (drawing W700760). A center column about $7 \mathrm{ft}$ in diameter supports the roof (drawing W704339). The entire tank volume is represented at a vertical resolution of 5 in. A variable lateral resolution is employed to capture steep gradients in the liquid level cone of depression at the salt well, which is approximately $36 \mathrm{in}$. in diameter. The smallest spacing, at the well, is 4 in. (Figure 8). Away from the well, the grid expands to a spacing of approximately $5 \mathrm{ft}$. Elements representing the well have a porosity of $100 \%$ and a hydraulic conductivity 1000 times greater than the surrounding saltcake. The latter is assumed to be homogeneous and isotropic. The initial liquid level in transient simulations was set to a maximum of 350 in., the saltcake level. The porosity above 350 in. was set to $1 \%$, so the volume above the saltcake does not impact the analysis. Based on the prior gravity equilibrium analysis, the saltcake properties were set to $30 \%$ porosity and a Sandy Loam water retention curve (Flach 2003a). Hydraulic conductivity was varied through model calibration to be discussed. Interstitial liquid removal was simulated by pumping from a 20 in. high well screen at the base of the salt well. Simulations were performed using a slightly modified version of FACT v2.0 (Hamm and Aleman 2000), which allowed for automatic time step adjustment.

The permeability of the saltcake was assumed to be uniform and isotropic for simplicity and due to a lack of characterization data to support a heterogeneous, anisotropic model. Although sample data, gamma scans from the tank annulus, and salt well mining experience indicate the saltcake is heterogeneous, tank characterization data are presently insufficient to quantitatively describe permeability variations throughout the tank. Thus, the model permeability value should be interpreted as the tank-wide average value of a physical permeability field that is heterogeneous in reality. Large scale non-uniformity would affect drainage behavior, but smaller scale variations would have little effect. Macroscopic anisotropy, resulting from the presence of distinct strata for example, would affect drainage behavior. 


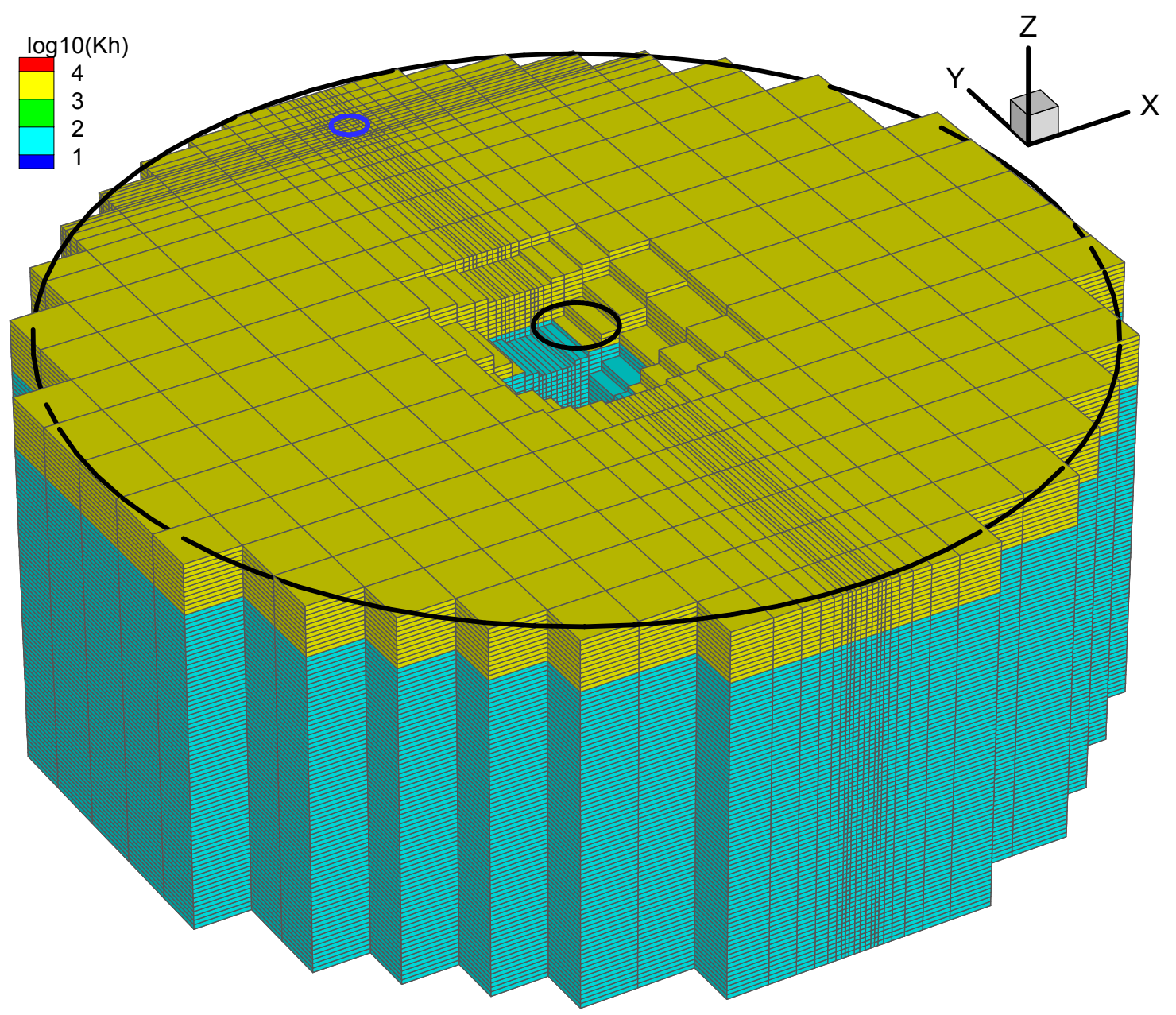

Figure $7 \quad$ Finite-element grid and material property specification for Tank 41 porous medium flow simulation; blue shading corresponds to saltcake, yellow/tan to air and/or supernate filled volume.

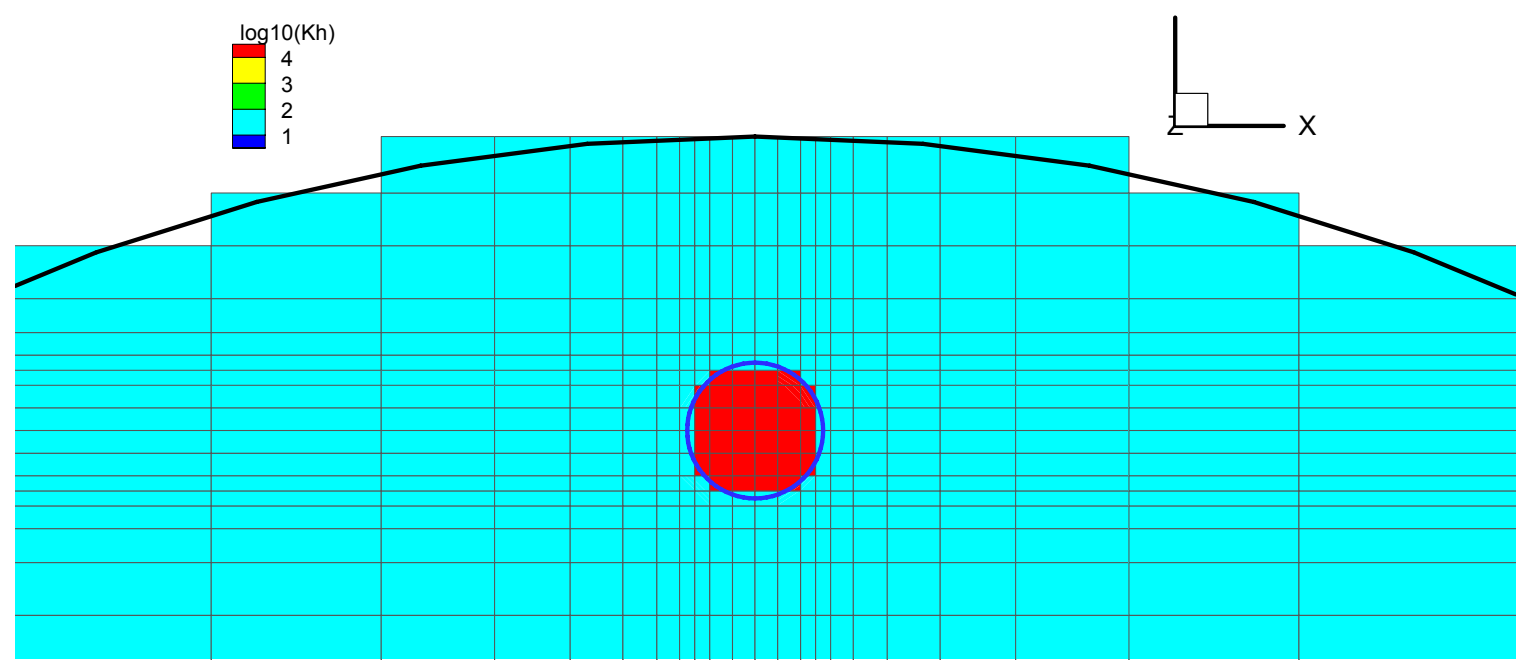

Figure 8 Finite-element grid and material property specification in the vicinity of the salt well beneath the Tank $41 \mathrm{C} 1$ riser. 


\section{Gravity equilibrium analysis for Tank 41}

Gravity equilibrium refers to a static liquid retention condition in which capillary suction is balanced with elevation head, and fluid movement ceases. That is, gravity equilibrium is the steady-state condition reached after a liquid level change in a porous medium. Gravity equilibrium analyses were performed previously using analytical expressions for the moisture profile to deduce the range of porous medium properties (porosity and liquid retention curve) that agree with Tank 41 drainage data (Flach 2003a). Consideration of other information lead to the best-estimate properties described previously (Flach 2003b)

As a model validation exercise, gravity equilibrium simulations were performed with the numerical analysis using the best-estimate properties, which are 30\% initial liquid content and a Sandy Loam water retention curve. An initial comparison revealed a small units conversion error in the prior work, which was corrected. Specifically the van Genuchten $\alpha$ parameter in units of $\mathrm{cm}^{-1}$ was originally converted to $\mathrm{ft}^{-1}$ using a multiplier of 25.4 in spreadsheets instead of the correct conversion of $30.48 \mathrm{~cm} / \mathrm{ft}$. This lead to about an error of a few percent in residual liquid volumes reported in Flach (2003a). After making this correction, the analytical and numerical model were compared at key liquid levels. As shown by Table 7, the two models produce essentially the same estimates, which agree reasonably well with the actual volumes transferred out of Tank 41.

Table 7 Actual volume pumped from Tank 41 compared to analytical and numerical estimates of the volume change for the same liquid level change.

\begin{tabular}{|c|cc|cc|cc|cc|}
\hline $\begin{array}{c}\text { Liquid Level } \\
\text { (in) }\end{array}$ & $\begin{array}{c}\text { Actual } \\
\text { Volume } \\
\text { Change } \\
\text { (gal) }\end{array}$ & $\begin{array}{c}\text { Difference } \\
\text { (gal) }\end{array}$ & $\begin{array}{c}\text { Liquid } \\
\text { Volume } \\
\text { (gal) }\end{array}$ & $\begin{array}{c}\text { Analytical } \\
\text { Volume } \\
\text { Change } \\
\text { (gal) }\end{array}$ & $\begin{array}{c}\text { Liquid } \\
\text { Volume } \\
\text { (gal) }\end{array}$ & $\begin{array}{c}\text { Numerical } \\
\text { Volume } \\
\text { Change } \\
\text { (gal) }\end{array}$ & $\begin{array}{c}\text { Porous medium } \\
\text { porosity }\end{array}$ & $\begin{array}{c}\text { Retention } \\
\text { curve }\end{array}$ \\
\hline 357 & 0 & & & 0 & & 0 & & \\
350 & $-25,000$ & & 369,176 & $-25,000$ & 367,161 & $-25,000$ & $30 \%$ & Sandy Loam \\
260 & $-68,472$ & 11,113 & 336,817 & $-57,359$ & 334,594 & $-57,567$ & $30 \%$ & Sandy Loam \\
160 & $-112,568$ & $-4,892$ & 276,716 & $-117,460$ & 274,332 & $-117,829$ & $30 \%$ & Sandy Loam \\
68 & $-173,938$ & $-5,520$ & 214,718 & $-179,458$ & 212,215 & $-179,946$ & $30 \%$ & Sandy Loam \\
\hline
\end{tabular}




\section{Average intrinsic permeability of saltcake in Tank 41}

The average intrinsic permeability of Tank 41 saltcake was estimated by calibrating hydraulic conductivity to well drawdown in response to pumping, and an estimate of the viscosity of the interstitial liquid. Hydraulic conductivity $(\mathrm{L} / \mathrm{T})$ is defined as

$$
\mathrm{K}=\frac{\rho \mathrm{gk}}{\mu}
$$

where $k=$ intrinsic permeability $\left(\mathrm{L}^{2}\right), \rho=$ fluid density $\left(\mathrm{M} / \mathrm{L}^{3}\right), \mu=$ fluid viscosity $(\mathrm{M} / \mathrm{L}-\mathrm{T})$ and $\mathrm{g}=$ gravitational acceleration $\left(\mathrm{L} / \mathrm{T}^{2}\right)$. Intrinsic permeability, a property of the porous medium that is not dependent on fluid properties, becomes

$$
\mathrm{k}=\frac{\mathrm{K} \mu}{\rho \mathrm{g}}
$$

The density and viscosity of the interstitial liquids in Tanks 3 and 41 at 20 and $50{ }^{\circ} \mathrm{C}$ were estimated by Dan McCabe using StreamAnalyzer (OLI Systems, Inc.; Appendix B). The temperatures of Tanks 41 and 3 were about 20 and $50{ }^{\circ} \mathrm{C}$, respectively. For completeness and tank-to-tank comparisons, viscosities at both temperatures for both tanks are given in Table 8 . Note that temperature is the primary cause of the $3 \times$ viscosity difference between Tanks 41 and 3, rather than chemical composition.

The Tank 41 well level and pumping rate transients for 285 days of operation starting 9/8/02 are plotted in Figures 9 and 10. Calibration of the finite-element numerical model to these data indicated the average saltcake hydraulic conductivity was in the range of 75 to 150 in/day, as shown by the comparisons shown in Figures 9 through 12. An example snapshot of the transient three-dimensional simulations is shown in Figure 13.

Figures 10 and 12 indicate that the numerical simulations closely reproduce the actual liquid volume removed with time. This is a result of a correctly specified pumping rate in the source/sink term representing the well, and sufficiently low numerical loss or gain of mass due to cumulative time/space discretization errors. The actual and simulated well levels were compared through Figures 9 and 11 to calibrate the numerical model by adjusting hydraulic conductivity.

In the $75 \mathrm{in} / \mathrm{d}$ simulation, reasonably good agreement is observed for the first half of tank drainage. However, the well becomes dry early in the third and final phase of Tank 41 interstitial liquid removal, indicating the model conductivity is too low. At $150 \mathrm{in} / \mathrm{d}$, the numerical model tends to under predict well drawdown. The two simulations appear to bound the range of conductivities needed to reproduce the actual well transient. In terms of intrinsic permeability, the equivalent range is 25 to 50 Darcy (Table 8). The midpoint 
of the range is approximately $110 \mathrm{in} / \mathrm{d}$ for hydraulic conductivity or 37 Darcy for intrinsic permeability, depending on the average taken, e.g., arithmetic or geometric. Geometric averaging is often used for log-normally distributed data, of which permeability is a common example. The appropriate average is not obvious, so the average of the two means was chosen.

Table 8 Viscosity and hydraulic conductivity estimates for Tanks 3 and 41 at 20 and $50^{\circ} \mathrm{C}$.

\begin{tabular}{|c|c|c|c|c|c|c|c|}
\hline Porosity & Soil Curve & $\begin{array}{l}\text { Conductivity } \\
(\mathrm{cm} / \mathrm{s})\end{array}$ & $\begin{array}{l}\text { Conductivity } \\
\text { (in/d) }\end{array}$ & $\begin{array}{l}\text { Density } \\
\left(\mathrm{g} / \mathrm{cm}^{3}\right)\end{array}$ & $\begin{array}{c}\text { Gravitational } \\
\text { acceleration } \\
\left(\mathrm{m} / \mathrm{s}^{2}\right)\end{array}$ & $\begin{array}{c}\text { Dynamic } \\
\text { viscosity } \\
(\mathrm{cP})\end{array}$ & $\begin{array}{c}\text { Permeability } \\
\text { (Darcy) }\end{array}$ \\
\hline \multicolumn{8}{|l|}{ Tank41 } \\
\hline & & & & & & $20 \mathrm{C}$ & \\
\hline $30 \%$ & SandyLoam & $2.2 \mathrm{E}-03$ & 75 & 1.43 & 9.81 & 15.8 & 25.2 \\
\hline \multirow[t]{2}{*}{$30 \%$} & SandyLoam & 4.4E-03 & 150 & 1.43 & 9.81 & 15.8 & 50.3 \\
\hline & & & & & & $50 \mathrm{C}$ & \\
\hline $30 \%$ & SandyLoam & 7.0E-03 & 239 & 1.38 & 9.81 & 4.8 & 25.2 \\
\hline $30 \%$ & SandyLoam & 1.4E-02 & 476 & 1.38 & 9.81 & 4.8 & 50.3 \\
\hline \multicolumn{8}{|l|}{ Tank03 } \\
\hline & & & & & & $20 \mathrm{C}$ & \\
\hline $30 \%$ & SandyLoam & 2.4E-03 & 80 & 1.39 & 9.81 & 14.4 & 25.2 \\
\hline \multirow[t]{2}{*}{$30 \%$} & SandyLoam & 4.7E-03 & 160 & 1.39 & 9.81 & 14.4 & 50.3 \\
\hline & & & & & & $50 \mathrm{C}$ & \\
\hline $30 \%$ & SandyLoam & 7.1E-03 & 240 & 1.36 & 9.81 & 4.7 & 25.2 \\
\hline $30 \%$ & SandyLoam & $1.4 \mathrm{E}-02$ & 479 & 1.36 & 9.81 & 4.7 & 50.3 \\
\hline
\end{tabular}




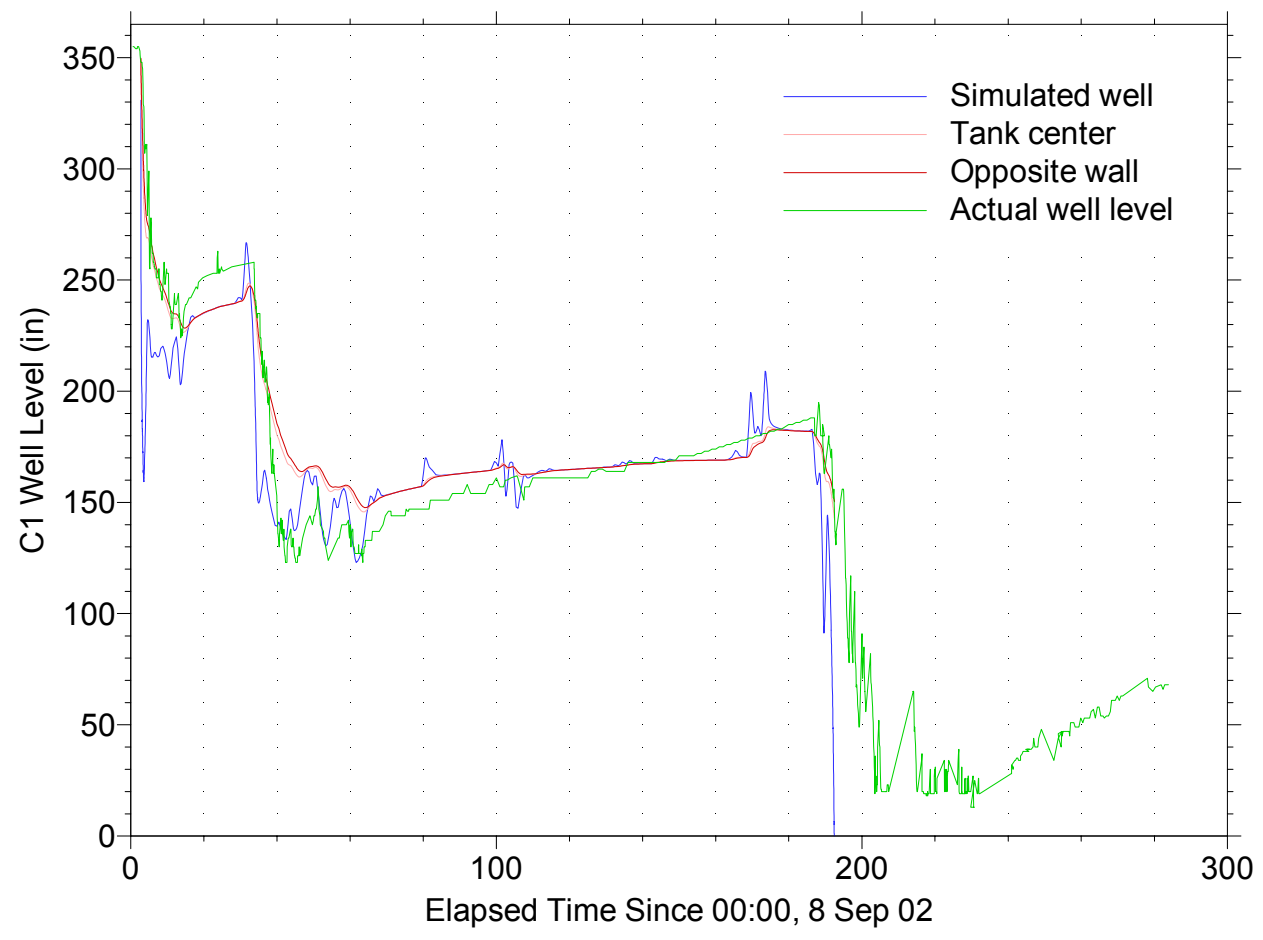

Figure 9 Actual and simulated liquid levels in Tank 41 for a hydraulic conductivity of $75 \mathrm{in} / \mathrm{d}$.

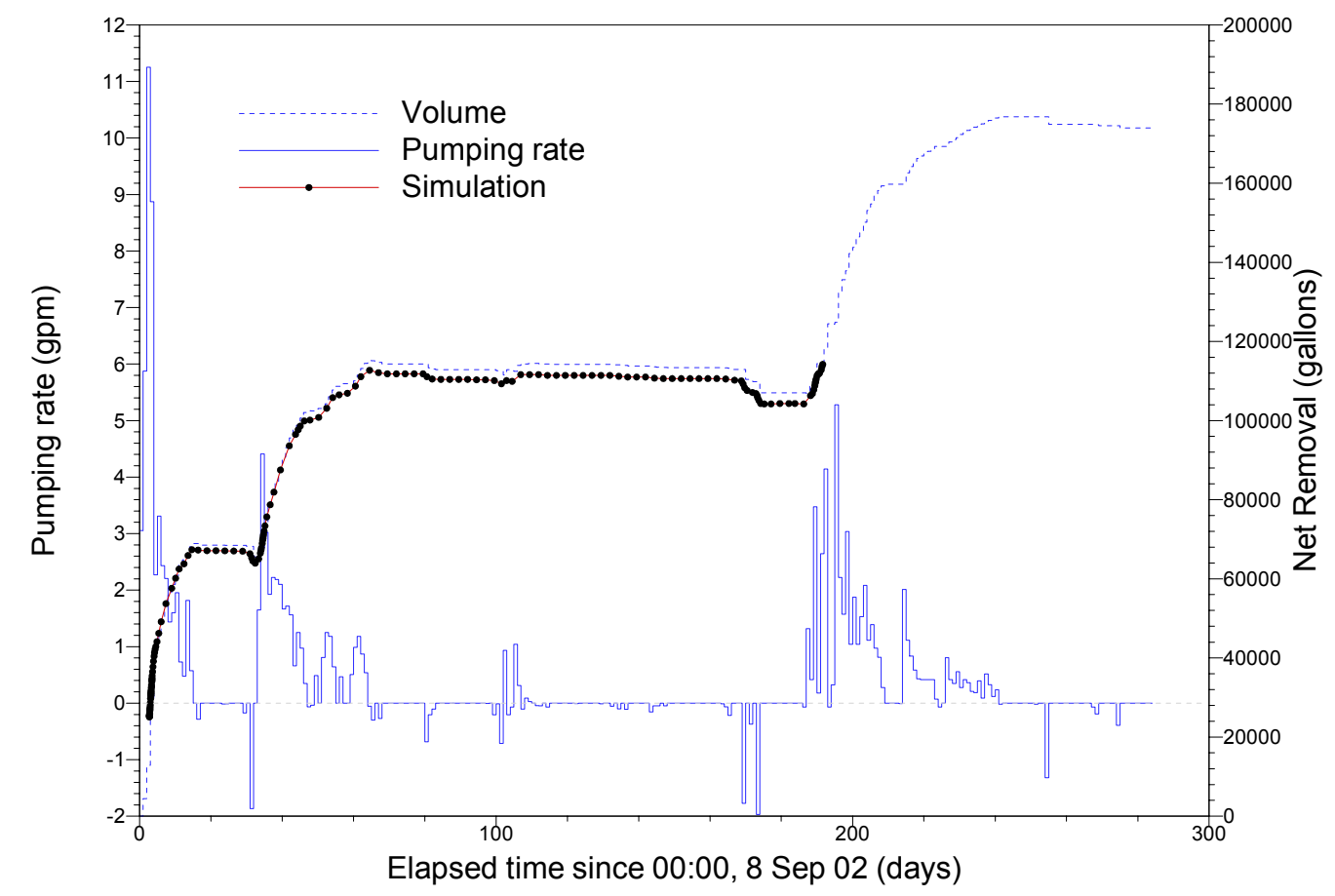

Figure 10 Actual and simulated volume changes in Tank 41 for a hydraulic conductivity of $75 \mathrm{in} / \mathrm{d}$. 


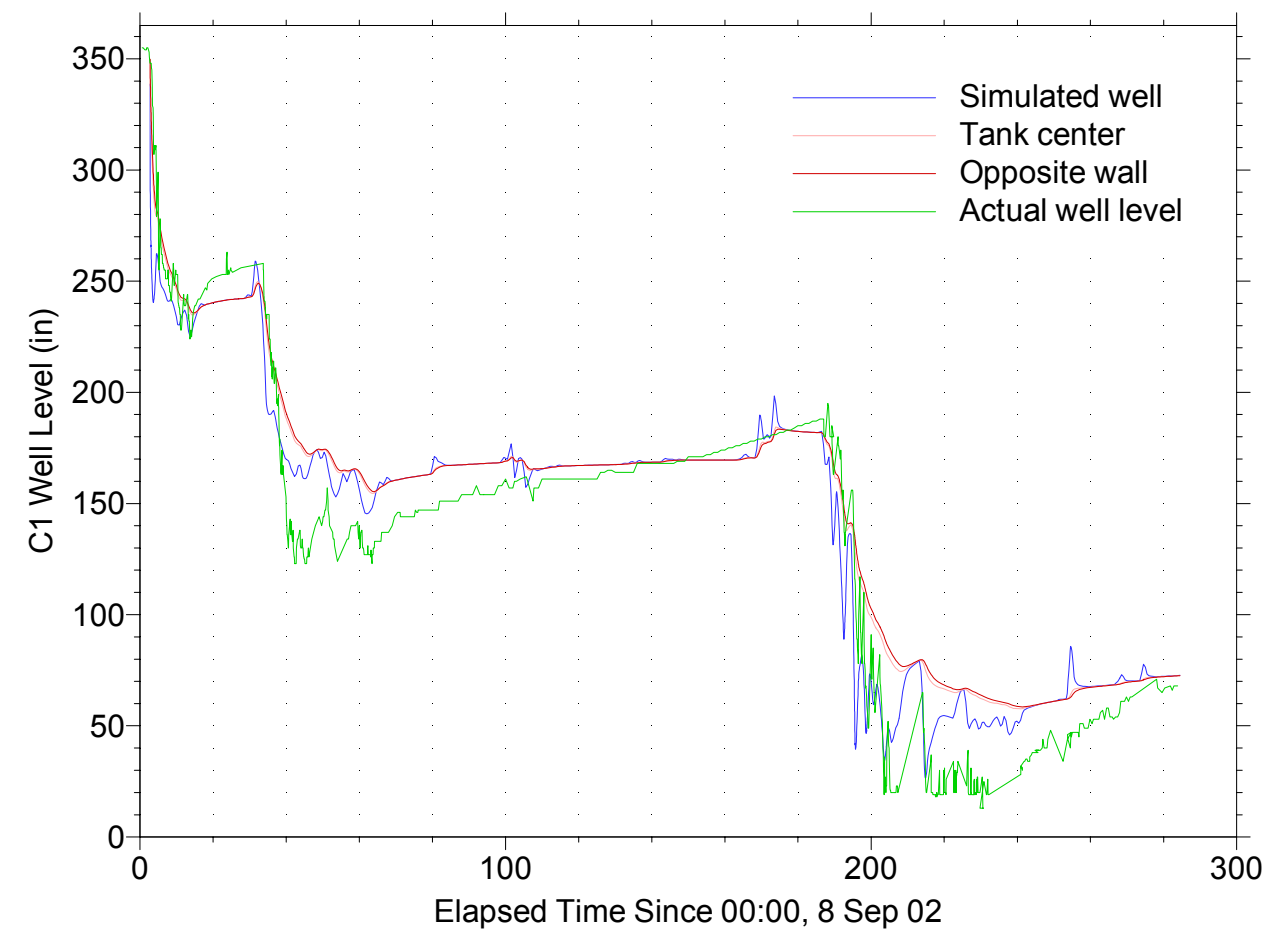

Figure 11 Actual and simulated liquid levels in Tank 41 for a hydraulic conductivity of $150 \mathrm{in} / \mathrm{d}$.

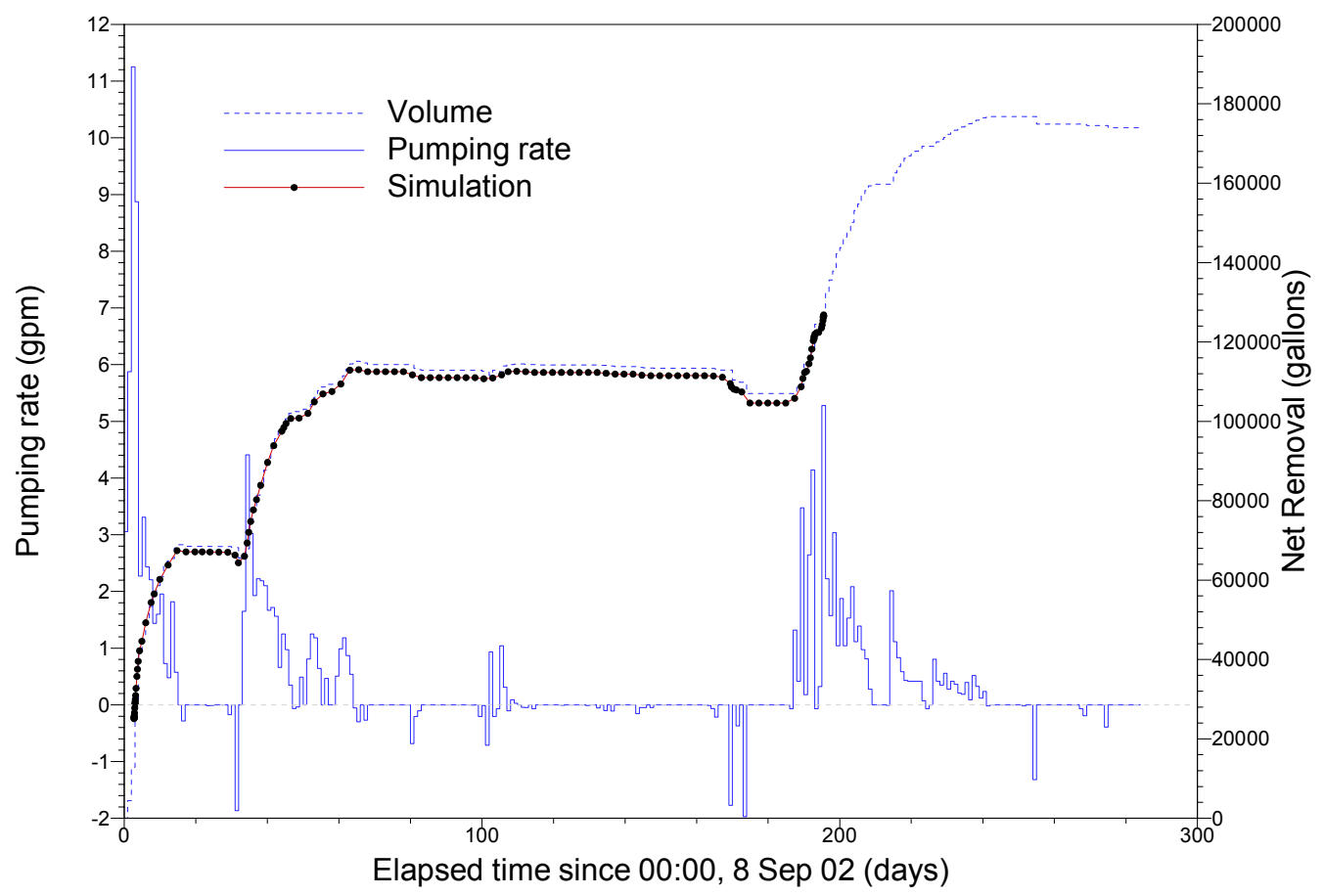

Figure 12 Actual and simulated volume changes in Tank 41 for a hydraulic conductivity of $150 \mathrm{in} / \mathrm{d}$. 


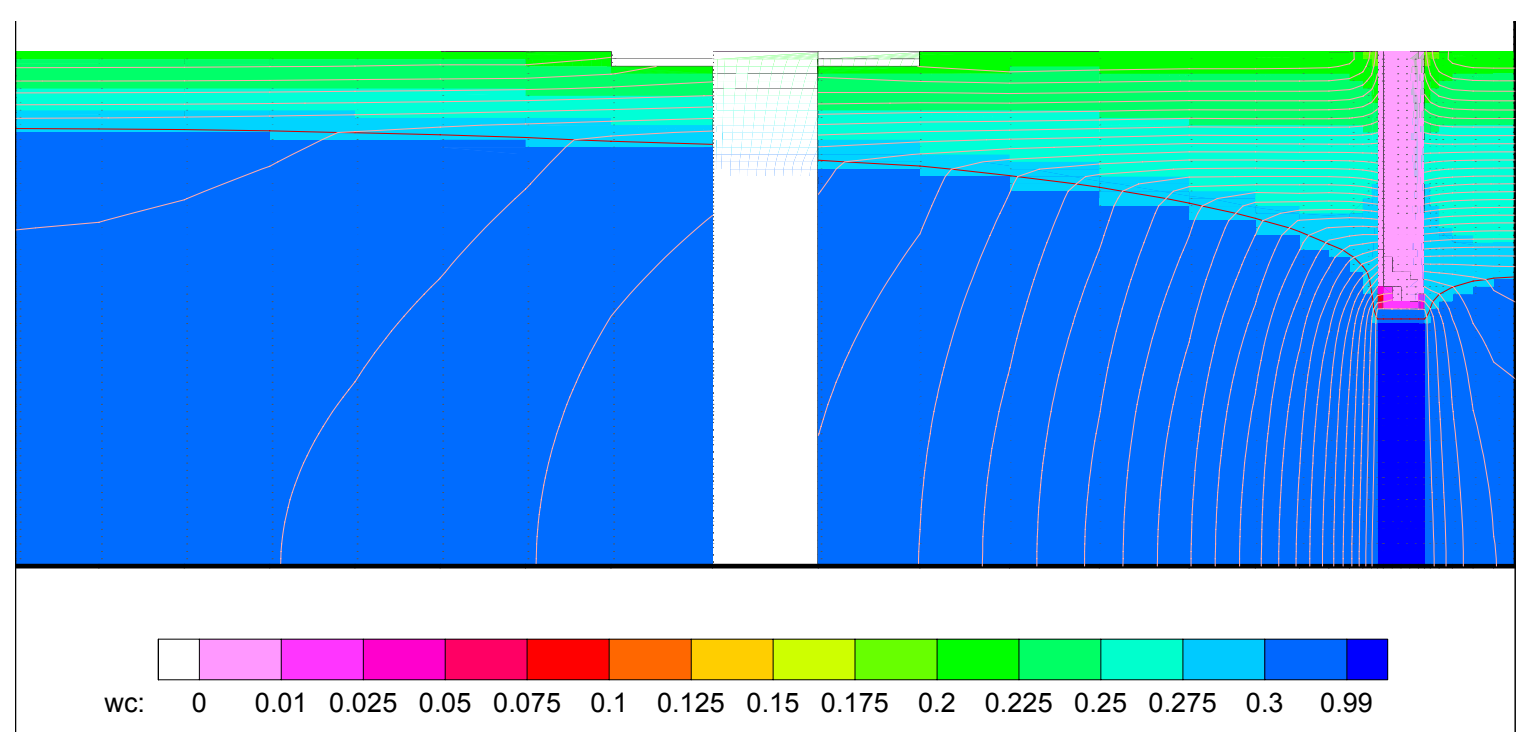

Figure 13 Snapshot of simulated liquid level, hydraulic head contours (5 in. intervals), and liquid content in Tank 41 at an elapsed time of 3.7 days for a hydraulic conductivity of $75 \mathrm{in} / \mathrm{d}$.

\section{Forecasts of Tank 3 interstitial liquid removal}

Unlike the analytical model, the finite-element numerical model can accommodate differences in tank geometry and fluid properties between tanks. If saltcakes are assumed to have the same intrinsic permeability as that in Tank 41, interstitial liquid removal from other salt tanks can be forecast. Such forecasts were performed for Tank 3 prior to any draining, and after model re-calibration to an initial phase of draining.

Intrinsic permeability is controlled by the physical structure of the porous media. Differences in saltcake physical attributes, such as particle/crystal size distribution and morphology, typically result in permeability differences. Saltcakes with similar chemical composition and tank operating history may be physically similar. The assumption that saltcakes have a similar intrinsic permeability as Tank 41 is a critical hypothesis that has not been validated in general. Thus, one purpose of the Tank 3 analysis is to assess whether this assumption is reasonable for SRS saltcakes.

\section{Numerical model}

Tank 3 is $75 \mathrm{ft}$ in diameter (drawing W146625) and $24.5 \mathrm{ft}$ high with 12 support columns of $2 \mathrm{ft}$ diameter (drawing W145573). Apart from taking up tank volume, the presence of the $2 \mathrm{ft}$ support columns was judged to be unimportant to interstitial flow through the 
saltcake because the columns are relatively small scale features. In the numerical model (Figure 14), the 12 physical columns were replaced with a hypothetical single center column of equivalent cross-sectional area. Because Tank 3 did not contain supernate above the salt level, the chosen mesh extends only to the saltcake height of $200 \mathrm{in}$. Salt wells of 16 in. diameter were considered beneath risers R1 and R5 by operations, so the mesh was refined in both areas in order to model head gradients at a well with sufficient accuracy. Experimentation with different mesh resolutions lead to a coarser mesh than used with Tank 41. The minimum horizontal spacing is $7 \mathrm{in}$. at both potential well locations (R1 and R5 risers; Figure 15), and the vertical resolution is 10 in. The coarser mesh for Tank 3 lead to roughly an order of magnitude improvement in computer run times.

The porosity and liquid retention curve specifications were the same as for Tank 41: 30\% and Sandy Loam. Intrinsic permeability for initial Tank 3 simulations was set to either 25 or 50 Darcy, comprising the range of values that produced the best results for different periods of Tank 41 drainage. The nominal temperature of Tank 3 was $50{ }^{\circ} \mathrm{C}$. Based on the fluid property estimates in Table 8, the hydraulic conductivity was set to either 240 or 480 in/d, corresponding to 25 or 50 Darcy. Note that the higher temperature leads to conductivity settings that are 3 times higher than the corresponding Tank 41 values. The interstitial liquid level was believed to be slightly below the saltcake level. The numerical model was initialized to a liquid level of 199 in. 


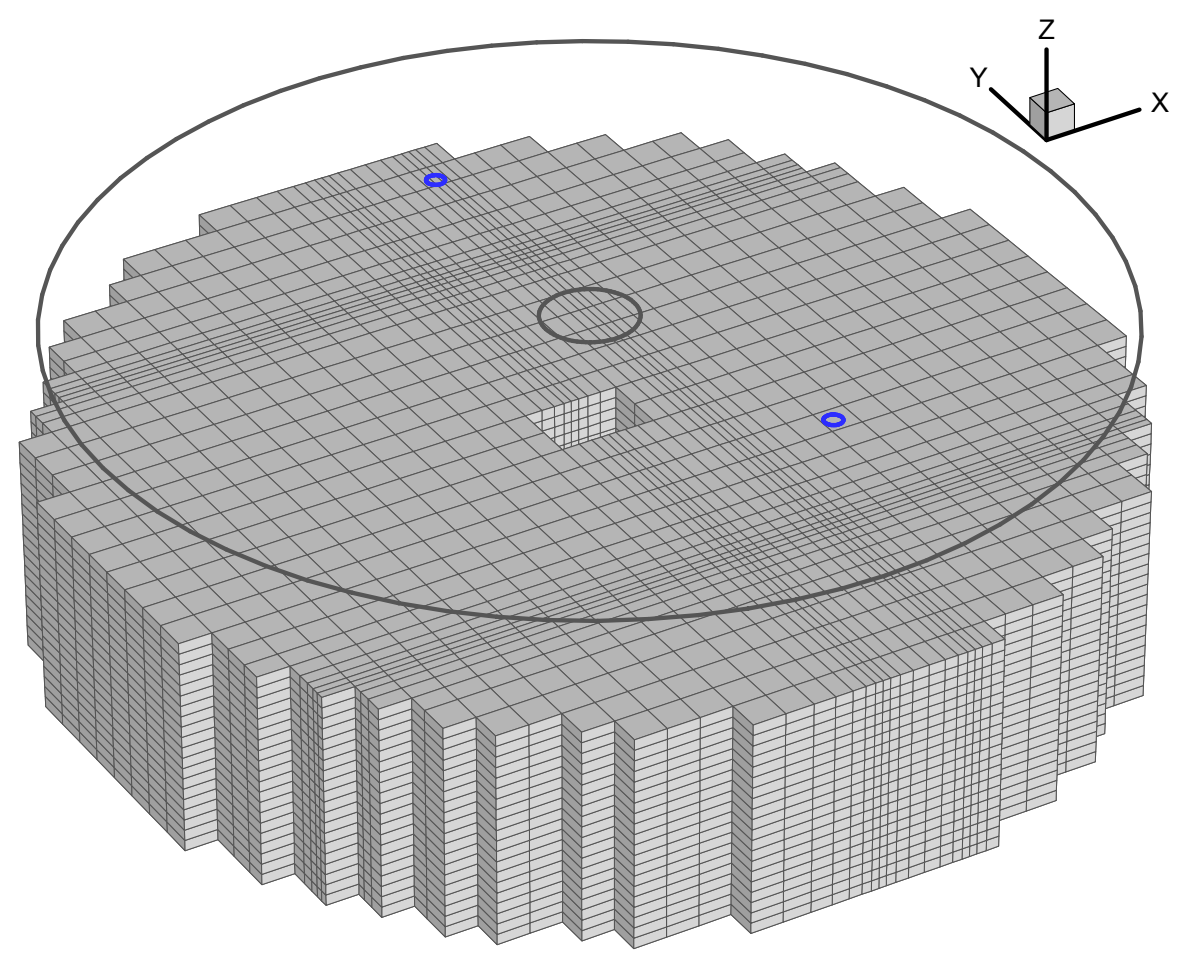

Figure 14 Finite-element grid for Tank 3 porous medium flow simulation; the center column is a hypothetical composite of 12 physical support columns.

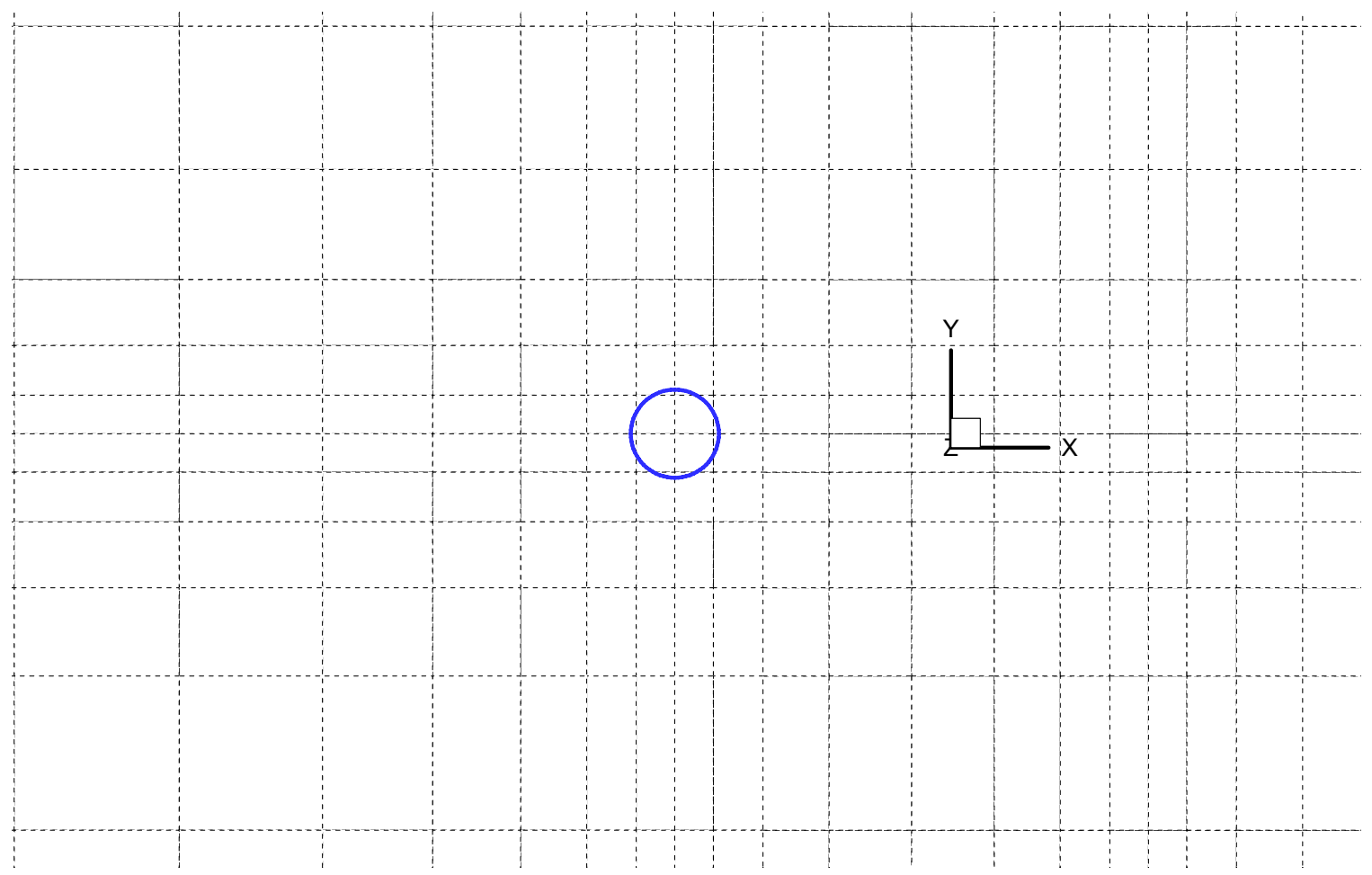

Figure 15 Finite-element mesh detail around Tank 3 salt well. 


\section{Value of adding a second well}

Simulations were performed for one and two salt wells/pumps to assess the value in decreased drainage time of adding an additional well. The well level was drawn down to $40 \mathrm{in}$. over the course of one day, and then held at that level for the duration of the 45 day simulation. Results are summarized by Figure 16. In the first few days of drainage, significantly more interstitial liquid removal occurs in the two well scenario. Towards the end of the 45 days allotted for drainage by operations, the cumulative volumes drained differ by only a few percent. For a 45 day operational window, little is gained by adding a second well.

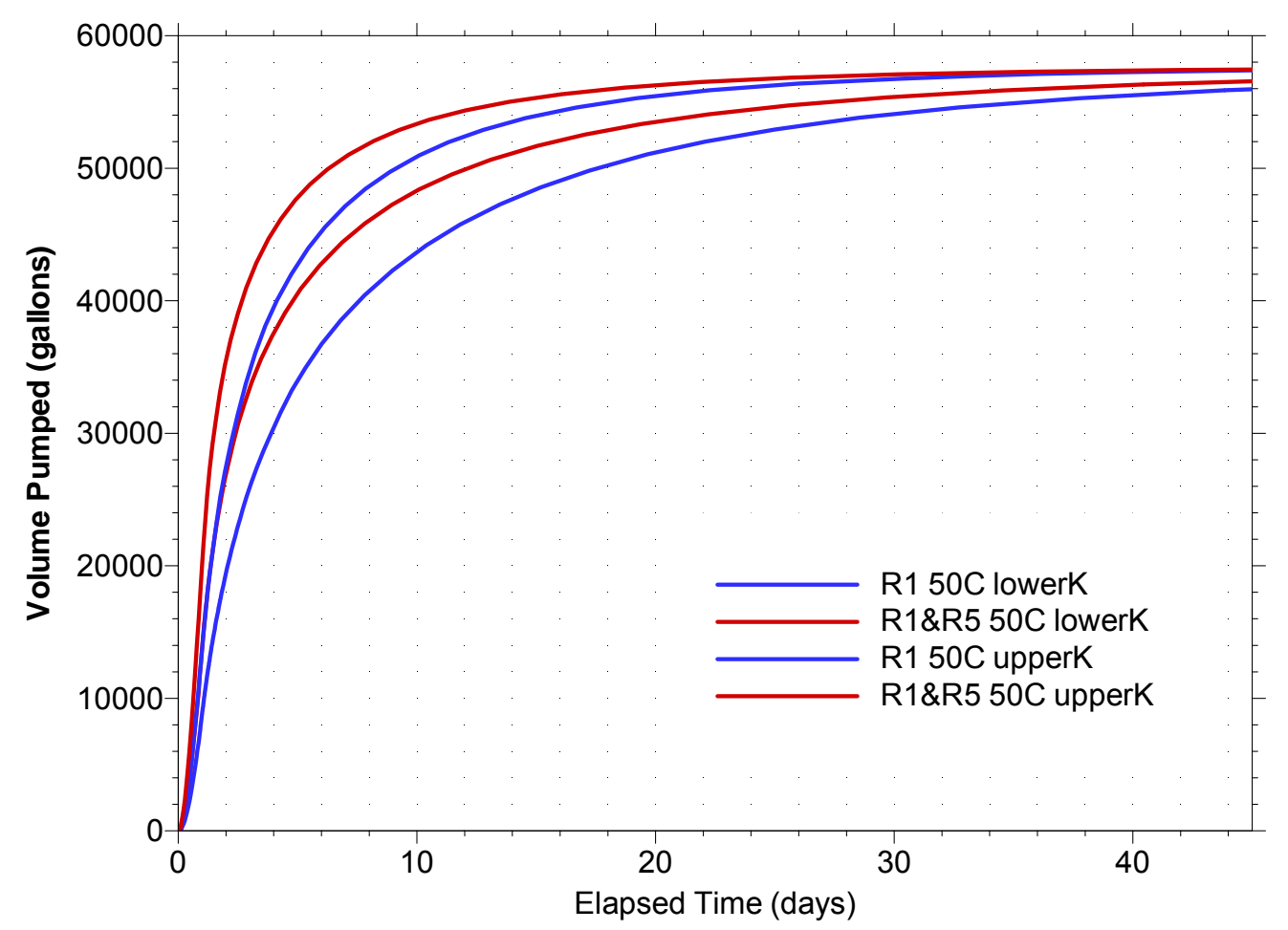

Figure 16 Simulated drainage of Tank 3 for one and two salt wells using low and high permeability estimates derived from Tank 41 (25 and 50 Darcy).

\section{Comparison to actual drain data}

Tank 3 interstitial liquid removal was initiated on 10/31/03 1800 hours with one salt well and pump. Figure 17 summarizes the anticipated drainage progress based on the preceding numerical simulation. Plant instrumentation indicated a starting well level of 188 in. rather than 199 in. After 4 days of pumping at roughly 7 gpm, 31,254 gallons of interstitial liquid had been removed and yet the well level was still at 167 in. (Figure 18). 
The observed behavior differed greatly from that anticipated and pumping was halted to investigate.

During the downtime, the well level remained stable and did not recover to a higher steady-state level as expected. A camera survey revealed approximately 50\% void space in the saltcake in the upper $3 \mathrm{ft}$ beneath a thin surface crust. Upon lowering of the interstitial level, a portion of the formerly continuous crust had subsided into the void space. Saltcake was observed surrounding the cooling coils. An analysis of the volume pumped and level change produced an estimated supernate pool fraction of $53 \%$, which is consistent with the visual observations (Table 9). The supernate pool was well-connected and thus offered insignificant resistance to flow, which explains the lack of well drawdown during pumping and recovery after shutdown.

Gamma scans of Tank 3 from the annulus (Moore 2003c) did not reveal the presence of supernate pools below the 200 in. saltcake crust level. Apparently saltcake on the tank wall masked the presence of subsurface supernate pools, but this explanation has not been confirmed. The average thickness of saltcake on cooling coils and the tank wall was estimated to be 18 in. (Table 9). That thickness would be expected to provide sufficient shielding.

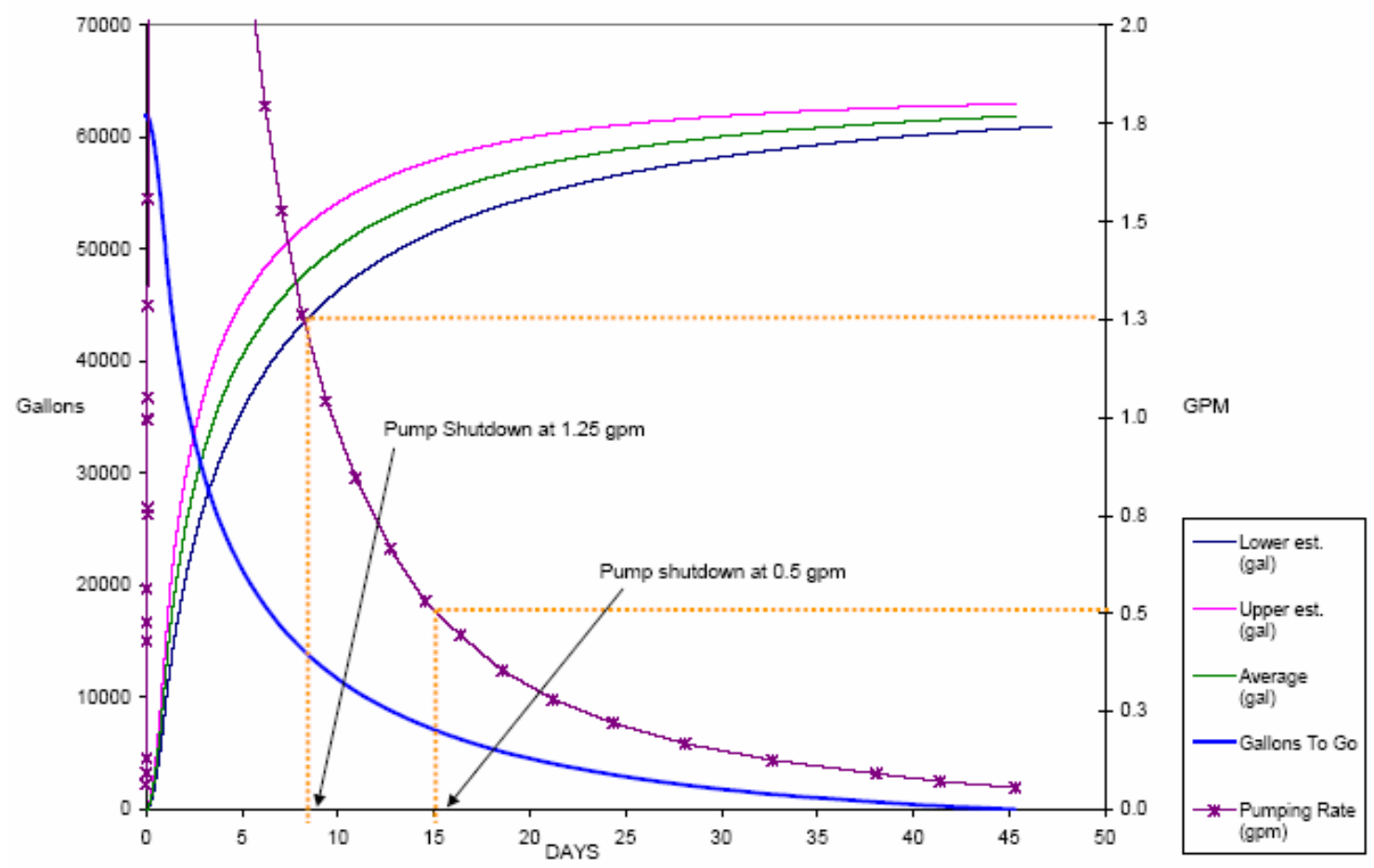

Figure 17 Anticipated interstitial liquid removal progress for Tank 3; reproduced from CBU-SPT-2003-00174. 


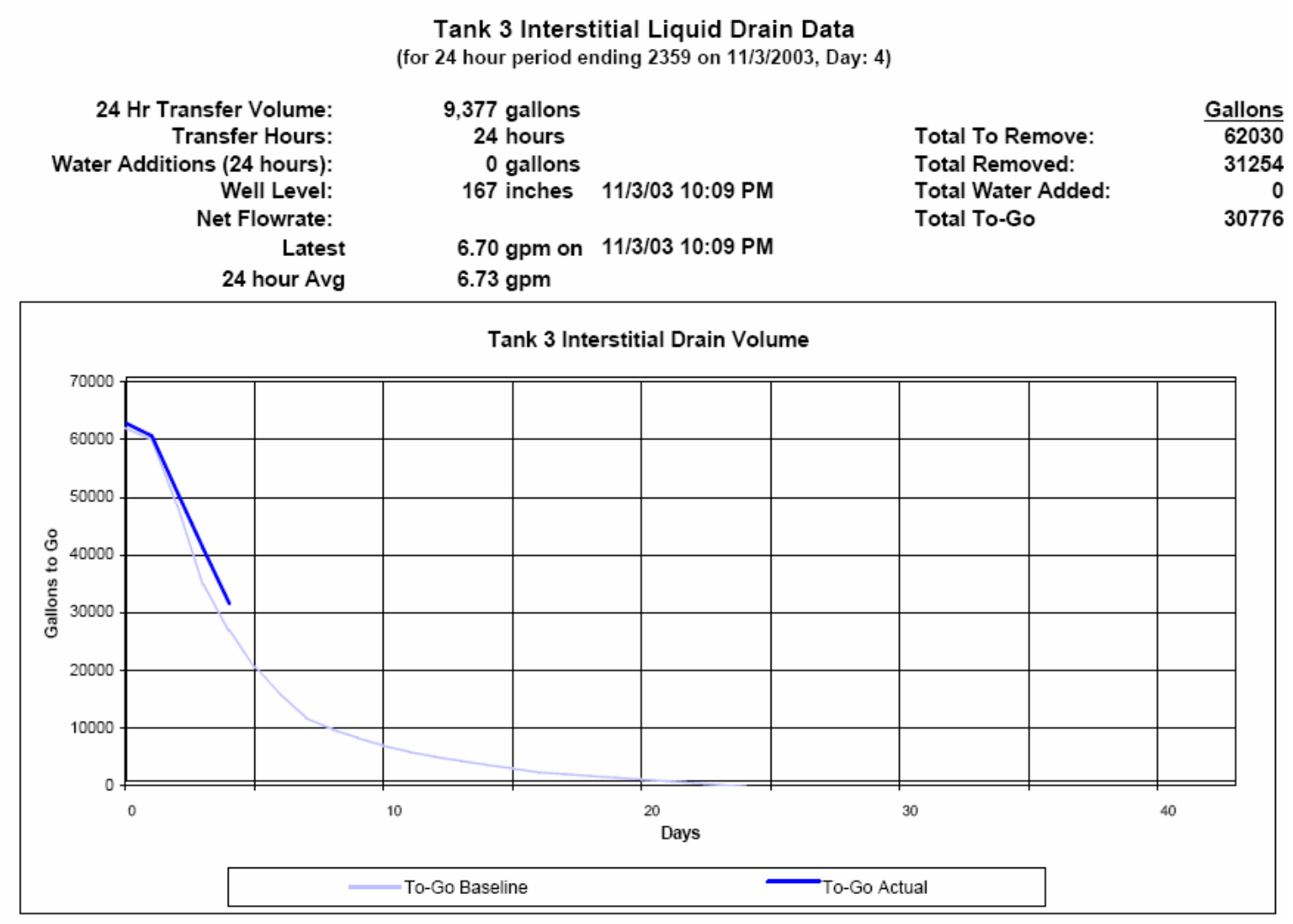

Figure 18 Day 4 morning report for Tank 3 interstitial liquid removal; reproduced from CBU-SPT-2003-00174. 
Table 9 Estimated volume fraction of supernate in pools in upper saltcake within Tank 3.

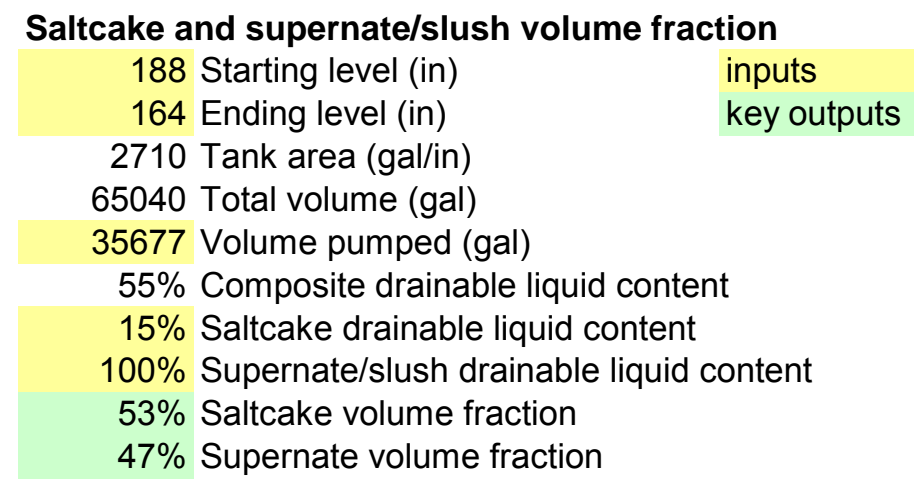

\section{Average saltcake thickness on tank wall and cooling coils 298 Number of coil pairs \\ 75 Tank diameter (ft) \\ 1.5 Saltcake radius/thickness ( $\mathrm{ft}$ ) 18 (in)}

\section{Revision to Tank 3 model}

To reflect the presence of macroscopic voids in the upper $40 \mathrm{in}$. of saltcake, the numerical model was revised to include the presence of 4 hypothetical cylinders of $100 \%$ porosity material between 160 in. and 200 in. (Figure 19). The hydraulic conductivity in the upper 40 in. was set to $100 \times$ that of the saltcake to reflect the highly permeable nature of the interconnected void space. Below 160 in. the saltcake hydraulic was set to a bestestimate of $339 \mathrm{in} / \mathrm{d}$, the geometric mean between the 240 and $480 \mathrm{in} / \mathrm{d}$ values derived from Tank 41 calibration. The starting well level was lowered from 199 in. to reflect the measurement of $188 \mathrm{in}$. It is not clear whether the actual well level was at $188 \mathrm{in}$., or if uncertainty in the specific gravity value used to correct the raw dip tube measurements produced a discrepancy. The fact that a thin surface crust subsided when pumping started suggests that the actual liquid level was closer to 199 in.

Concurrently, interstitial liquid removal from Tank 3 was resumed (Figure 20). During the second phase of drainage, significant drawdown was observed in the well (Figure 21), suggesting the absence of well-connected macroscopic voids in the saltcake below about 160 in. Simulation results from the revised Tank 3 were compared to actual well drawdown for both phases of drainage. As shown by Figure 21, reasonably good agreement is achieved using the best-estimate permeability value from Tank 41. This suggests that the saltcake in Tank 3 is more or less "solid" below about 160 in. and that the saltcakes in Tanks 41 and 3 have about the same intrinsic permeability. 
Barring unforeseen supernate layers/pockets, numerical forecast of drainage of other salt tanks of similar composition looks promising. Nevertheless, the experience gained with Tanks 41 and 3 is insufficient to validate or invalidate the assumption of similar hydraulic properties among salt tanks. It should also be noted that significantly different physical properties of saltcakes have been observed at the Hanford site.

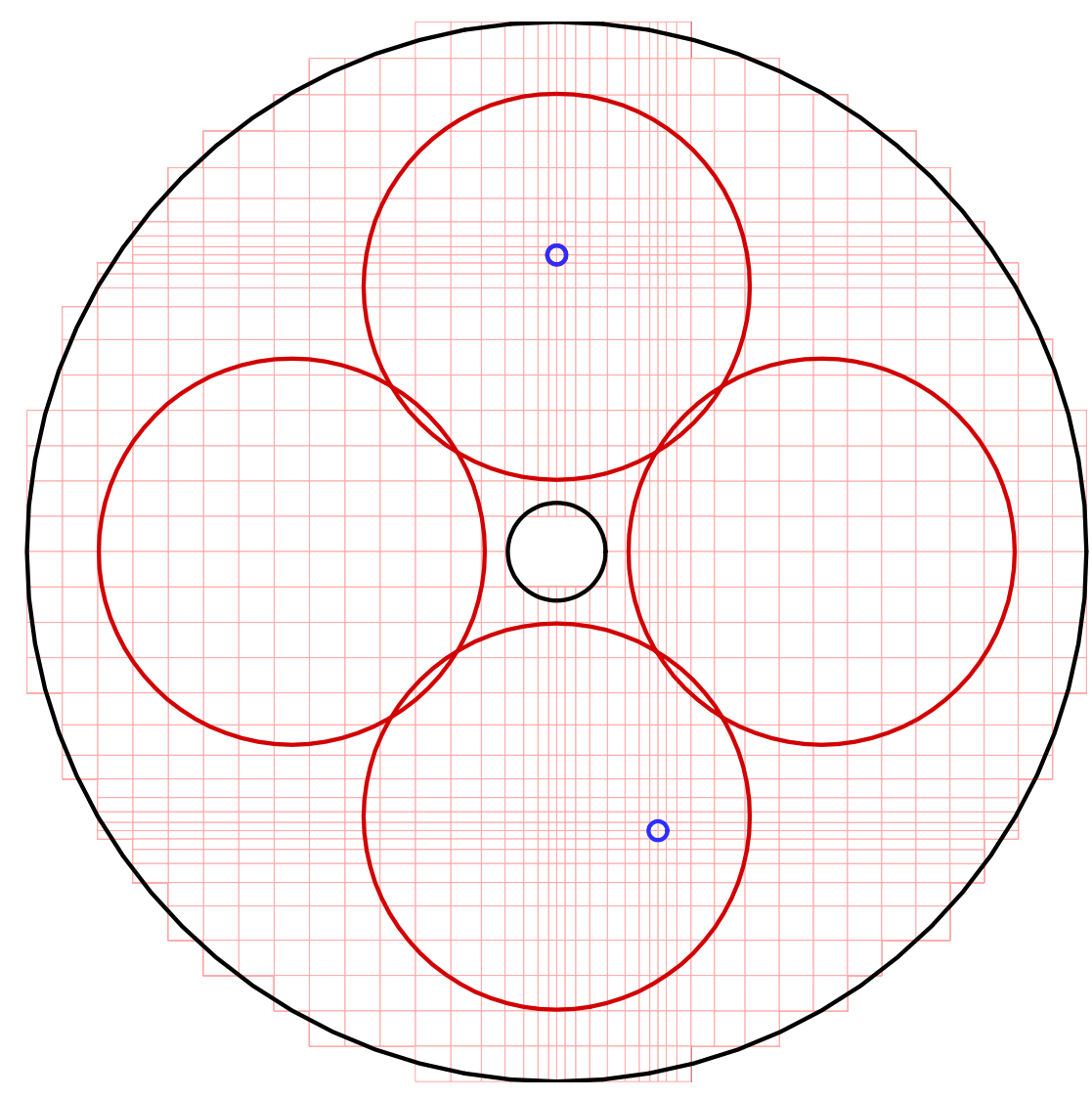

Figure 19 Hypothetical rings of $100 \%$ porosity material representing the composite effect of 53\% macroscopic voids in the upper Tank 3 saltcake. 


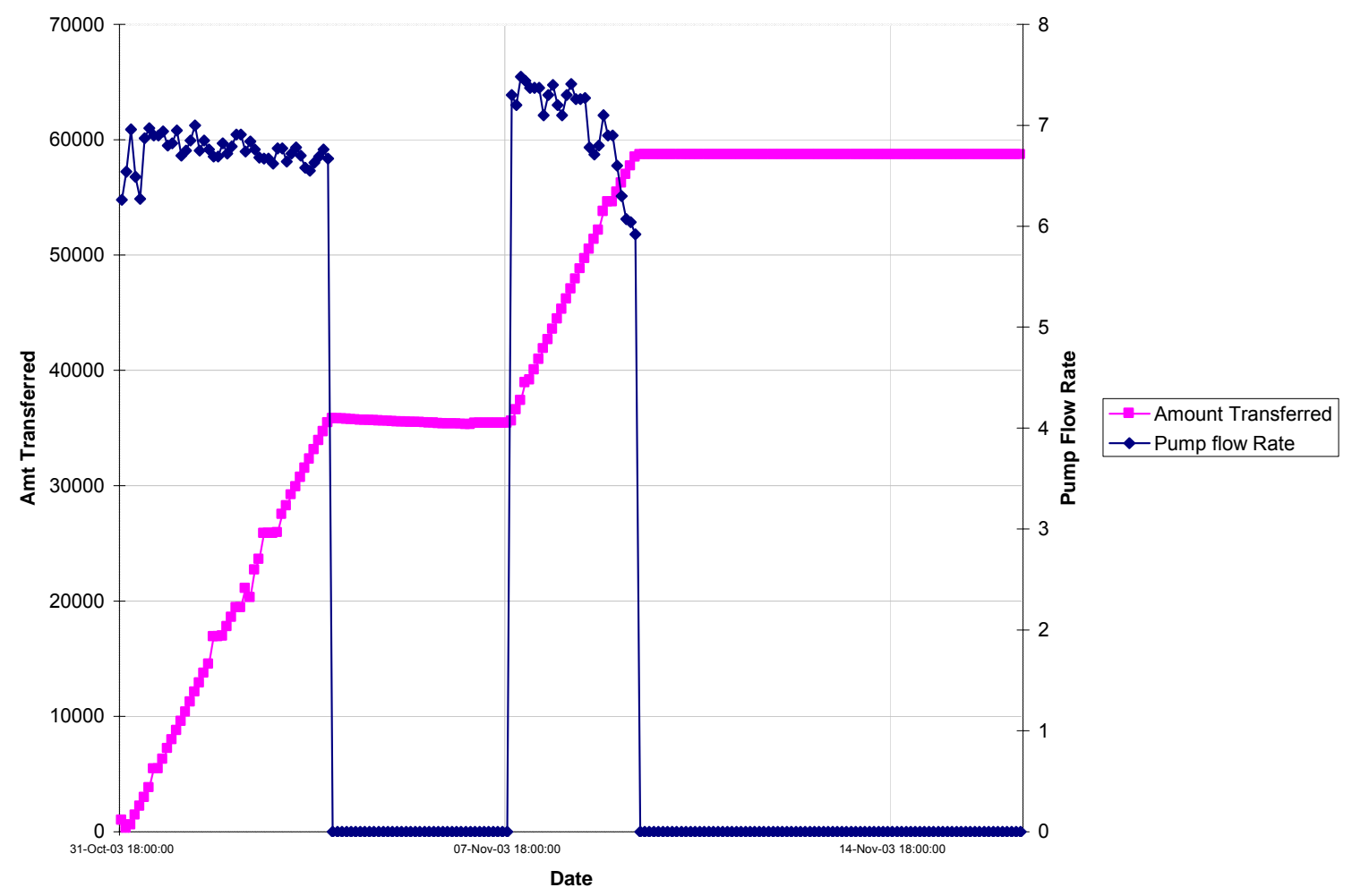

(a)

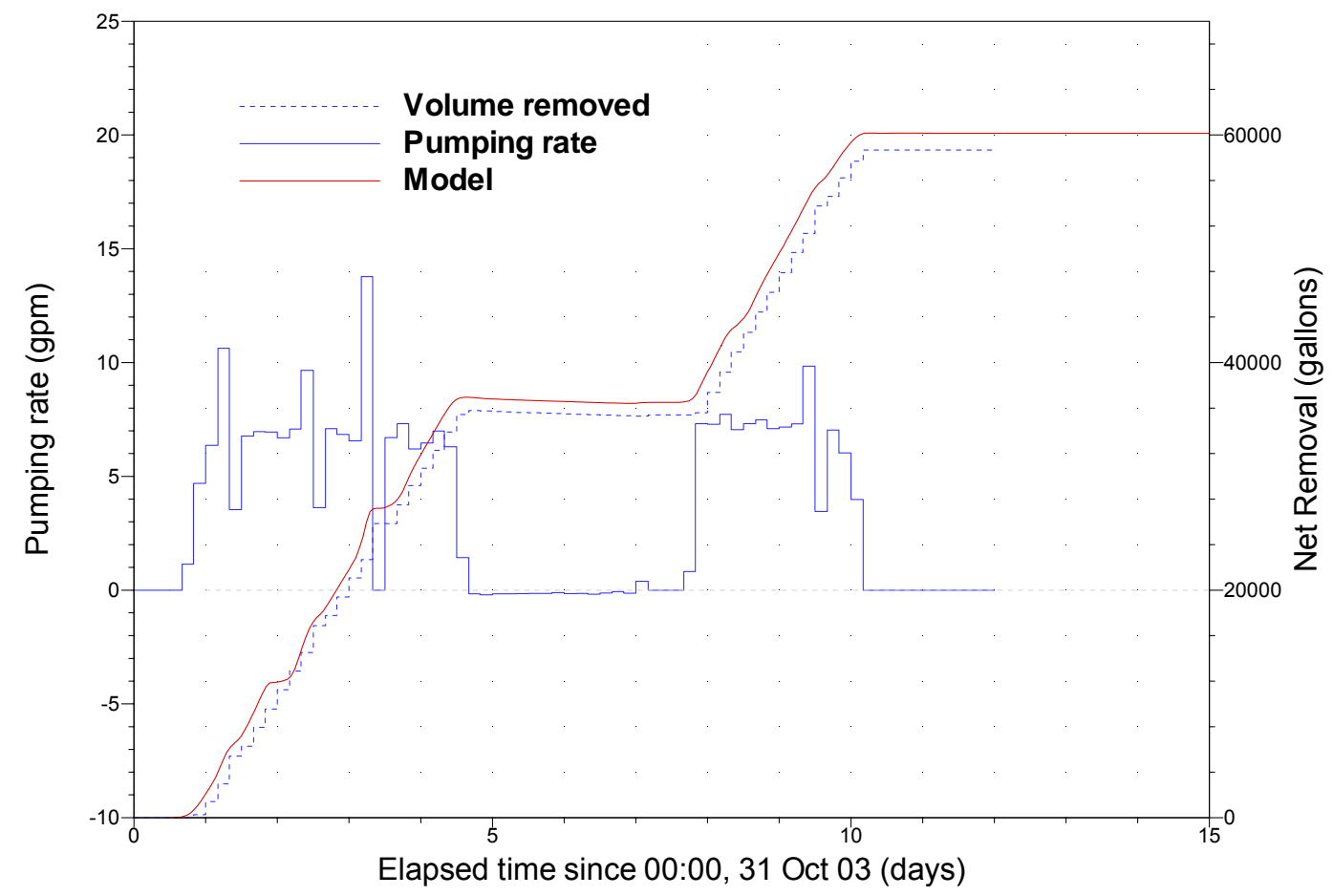

(b)

Figure 20 Pumping rate and interstitial liquid volume removed for Tank 3: a) facility operations data, and b) as modeled at 4 hour resolution with pumping rate computed from cumulative volume pumped. 


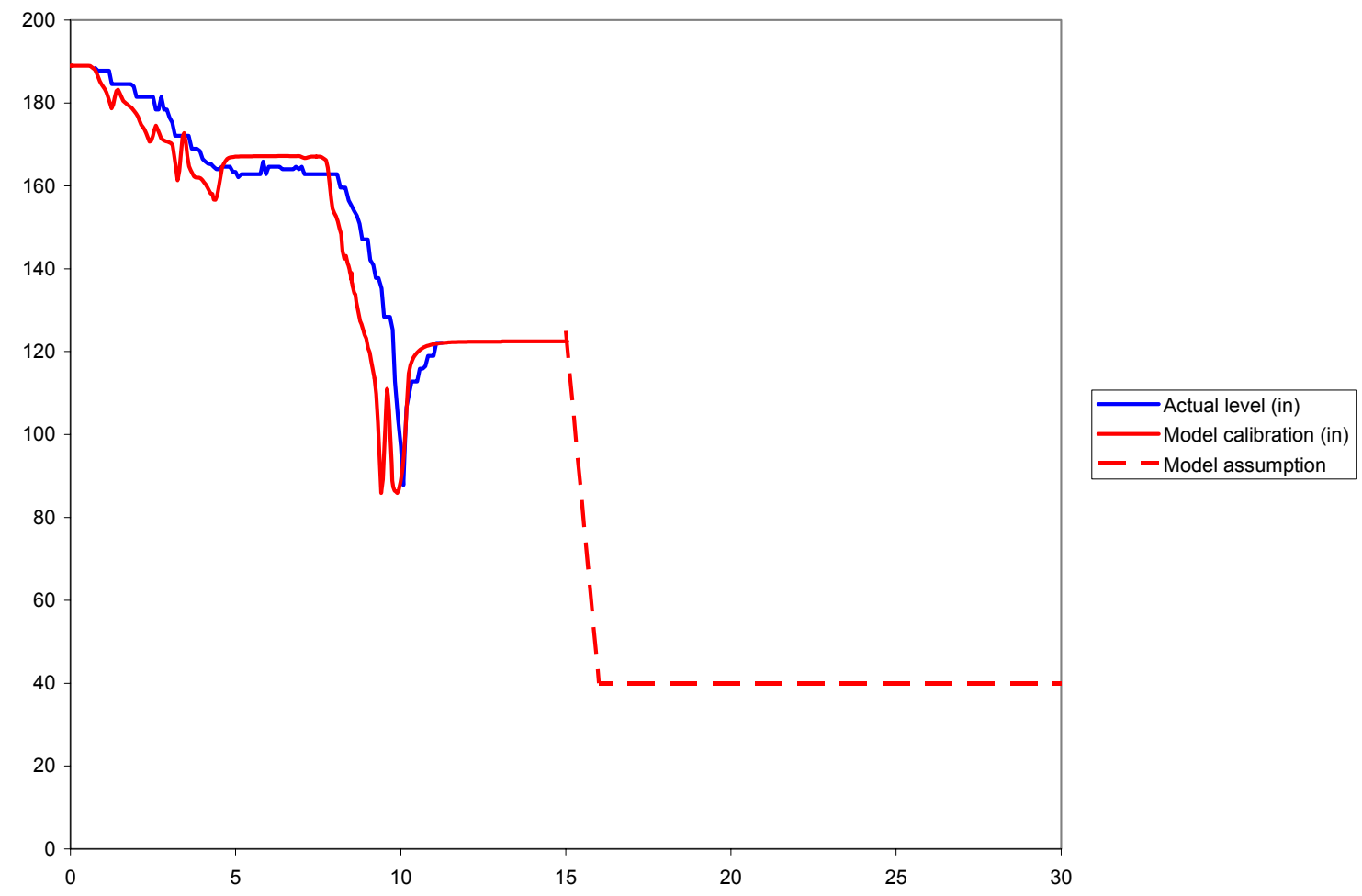

Figure 21 Actual and predicted well levels during Tank 3 drainage. 


\section{Comparison to physical property measurements on saltcake samples}

Drained saltcake samples from Tanks 41 and 3 were subjected to testing in the SRTC shielded cells to measure physical properties, such as porosity and intrinsic permeability. For Tank 41, the drained saltcake was found to have a permeability of 0.13 Darcy, a bulk density of $1.9 \mathrm{~g} / \mathrm{cm}^{3}$, a porosity of $22 \%$, and an "as-received" saturation of $34 \%$ (Nichols and Martino 2003). The latter corresponds to a residual liquid content of $34 \% \times 22 \%=$ 7.5\%. The porosity and saturation measurements are a factor of 2 lower than the estimates given in Table 1, and the permeability measurement is 2.5 orders of magnitude lower than the 37 Darcy estimate derived from numerical model calibration effort. Tank 3 sample measurements have not been published yet, but preliminary data indicate similar discrepancies between the two types of information.

The discrepancy between the small-scale samples and tank-wide averages is apparently a manifestation of heterogeneity. The samples were taken near the surface of the saltcake, a relatively cool zone that is believed to produce a denser saltcake. Saltcake near cooling coils is also thought to be less porous. Salt well mining and gamma scans from the periphery of the tank indicate the presence of hard layers at certain elevations. Thus it is not surprising to see local property values that differ significantly from the tank average / large scale estimates. Given that permeability typically varies over many orders of magnitude for natural and engineered materials, the two plus order of magnitude difference between the permeability estimates is not abnormal. The value derived from numerical modeling is the preferred estimate for average permeability. The sample measurements help define variability about the average, i.e. heterogeneity.

\section{Characterization and model development needs}

Prediction of interstitial liquid volume and saltcake mass is important for planning and optimizing liquid transfers in the F- and H-area tank farms. Experience at Hanford and recent SRS experience with Tank 3 indicate that layers and/or pockets of "free" supernate beneath the saltcake surface should be expected. The presence of such regions of pure liquid can have a significant impact on interstitial liquid removal. The initial estimate of volume to be removed for Tank 3 was approximately 60,000 gallons. A revised estimate, reflecting the newly discovered supernate pool, is roughly 90,000 gallons, a 50\% increase. The presence of supernate pools also strongly affected well levels during both the drawdown and recovery phases. Identification of supernate pools is important to accurately forecasting drainage volumes and times. Drainage times are also affected by interstitial fluid viscosity, which recent shielded cell laboratory work indicates may be more variable across tanks than originally thought. 
Cone Penetration Testing (CPT) technology, such as the recently acquired "ram-set" tool, could be used to address both characterization needs. The force required to advance the CPT rod into the saltcake could be monitored for a qualitative indication of saltcake presence or absence and density. Dry wells could be installed to allow gamma monitoring of the tank interior, in addition to the periphery from the annulus. The ram-set CPT tool can deploy a wire-line sampler for acquiring saltcake and liquid samples for subsequent shield cell laboratory analysis (e.g. liquid viscosity).

The effectiveness of washing / interstitial liquid displacement (ILD) processes under consideration is expected to depend strongly on the physical and chemical heterogeneity in salt tanks. Historically, samples have been taken almost exclusively at or slightly below the saltcake surface. Sampling and/or monitoring at depth from multiple risers is needed to characterize the degree of heterogeneity in a tank. In addition, the current numerical model cannot account for dissolution chemistry nor varying fluid compositions resulting from flush water addition. Additional model development is needed in order to have a predictive capability for coupled dissolution and porous medium transport. Such a capability could be used to select and optimize an effective washing / ILD process.

\section{Conclusions}

When calibration data are available to calibrate the analytical drain model, subsequent predictions can be expected to be good, as long as pumping was steady. Based on numerical modeling, the average intrinsic permeability of the saltcake in Tanks 41 and 3 appears to lie in the range of 25 to 50 Darcy. A best-estimate is 37 Darcy. Because the saltcakes in the two tanks appear to share porous medium properties, saltcakes of similar chemical composition are likely to have the similar physical properties. Thus, the prospect of achieving reasonably good drainage forecasts for other salt tanks looks promising in general. However, the presence of unknown/undefined macroscopic voids in the saltcake would lead to significant prediction errors, as was observed for the upper 40 in. in Tank 3. Characterization of such supernate-filled pockets would be highly beneficial toward accurately estimating drain volumes and progress. Characterization and detection of such supernate-filled pockets could be identified using Cone Penetration Testing (CPT) technology and gamma monitoring in the tank interior. Cost benefit and risk analysis can be used to determine the data needed to characterize a tank prior to draining. Little benefit is predicted for Tank 3 by installing a second salt well pump if a 45 day drainage period is utilized. 


\section{References}

Brass, E. A., 2003, Definition of success for Tank 3 interstitial liquid removal (U), memorandum CBU-SPT-2003-00174.

Drawings W145573, W146625, W700760 and W704339.

Drumm, M. D. and M. D. Hopkins, 2003, Feed Basis for Processing Relatively Low Radioactivity Waste Tanks, WSRC-TR-2001-00559, Rev. 3.

Flach, G. P., 2003a, Porous medium analysis of Tank 41 drain operations (U), technical report WSRC-TR-2003-00080, Rev. 0.

Flach, G. P., 2003b, Best-estimates of Tank 41H saltcake porous medium physical properties, memorandum SRT-EST-2003-00065.

Hamm, L. L. and S. E. Aleman, 2000, FACT (version 2.0); Subsurface Flow and Contaminant Transport documentation and user's guide (U), technical report WSRC-TR-99-00282, Rev. 0.

Hester, J. R., 2003, Bulk salt dissolution in Tank 41-H by the feed and bleed method, Engineering Calculation U-CLC-G-00012.

Martino, C. J., 2003, Initial results of the Tank 41H C1/C3-Riser supernate sample analysis, SRT-LWP-2003-00096, Rev. 1, November 4.

Martino, C. J. and R. L. Nichols, 2003, Tank 41H drained saltcake core sample analysis (HTF-E-03-033 - HTF-E-03-035), WSRC-TR-2003-00227, Rev. 0.

Martino, C. J., W. R. Wilmarth, D. P. Diprete and C. C. Diprete, 2003, Tank 41H dissolved saltcake sample (HTF-E-03-91-92) Saltstone Waste Acceptance Criteria analysis, WSRC-TR-2003-00380, Rev. 1.

Moore, F. S., 2003a, June 2003 Tank 41 annulus gamma monitor measurement report (U), SRT-ADS-2003-0356, Rev. 1.

Moore, F. S., 2003b, July 2003 Tank 41 annulus gamma monitor measurement report (U), SRT-ADS-2003-0395, Rev. 1.

Moore, F. S., 2003c, Tank 3 annulus gamma monitor measurement report rev. 1 (U), SRT-ADS-2003-0354, Rev. 1. 
Nichols, R. L. and C. J. Martino, 2003, Hydraulic properties of saltcake samples from Tank T41H (U), WSRC-TR-2003-00543, Rev. 0.

Romanowski, L. B., 2003, Tank 41 Low Curie Salt Process History and Data Analysis, CBU-SPT-2003-00224, Rev. 0. 


\section{Appendix A - Tank 41 dissolution and refill mixing calculations}

No mixing above 103 in.:

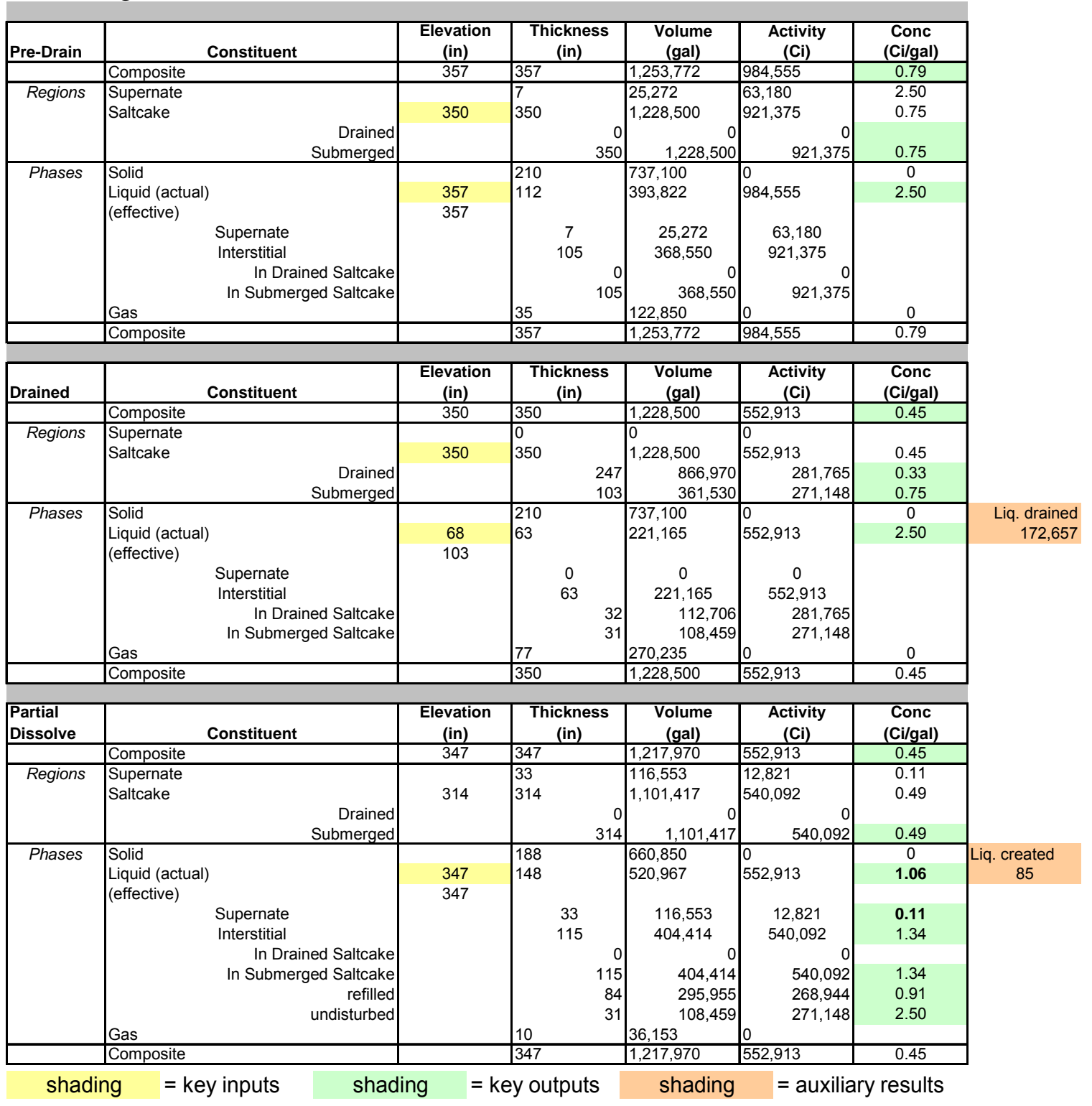


Partial mixing above 103 in.:

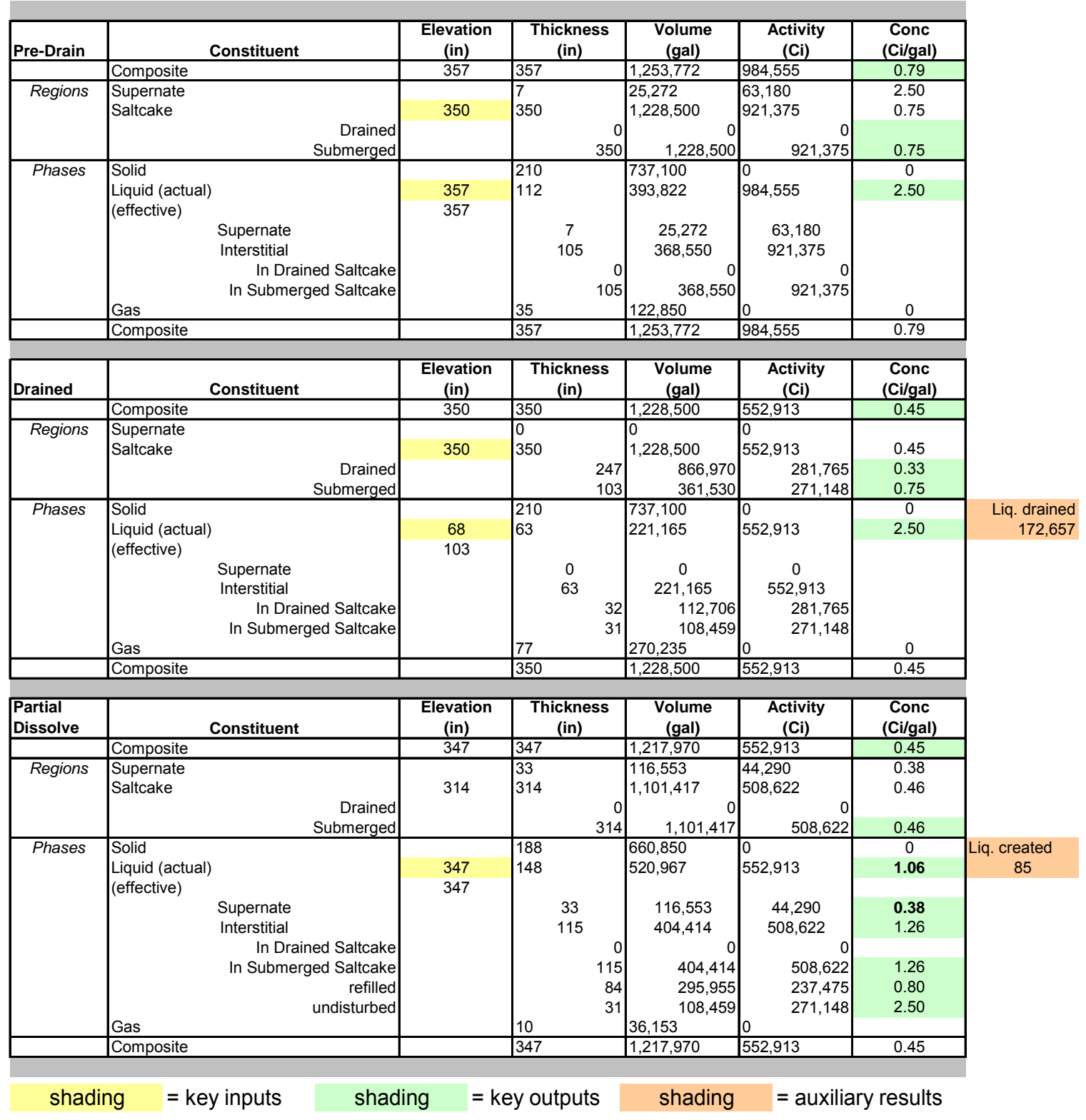


Complete mixing above 103 in.:

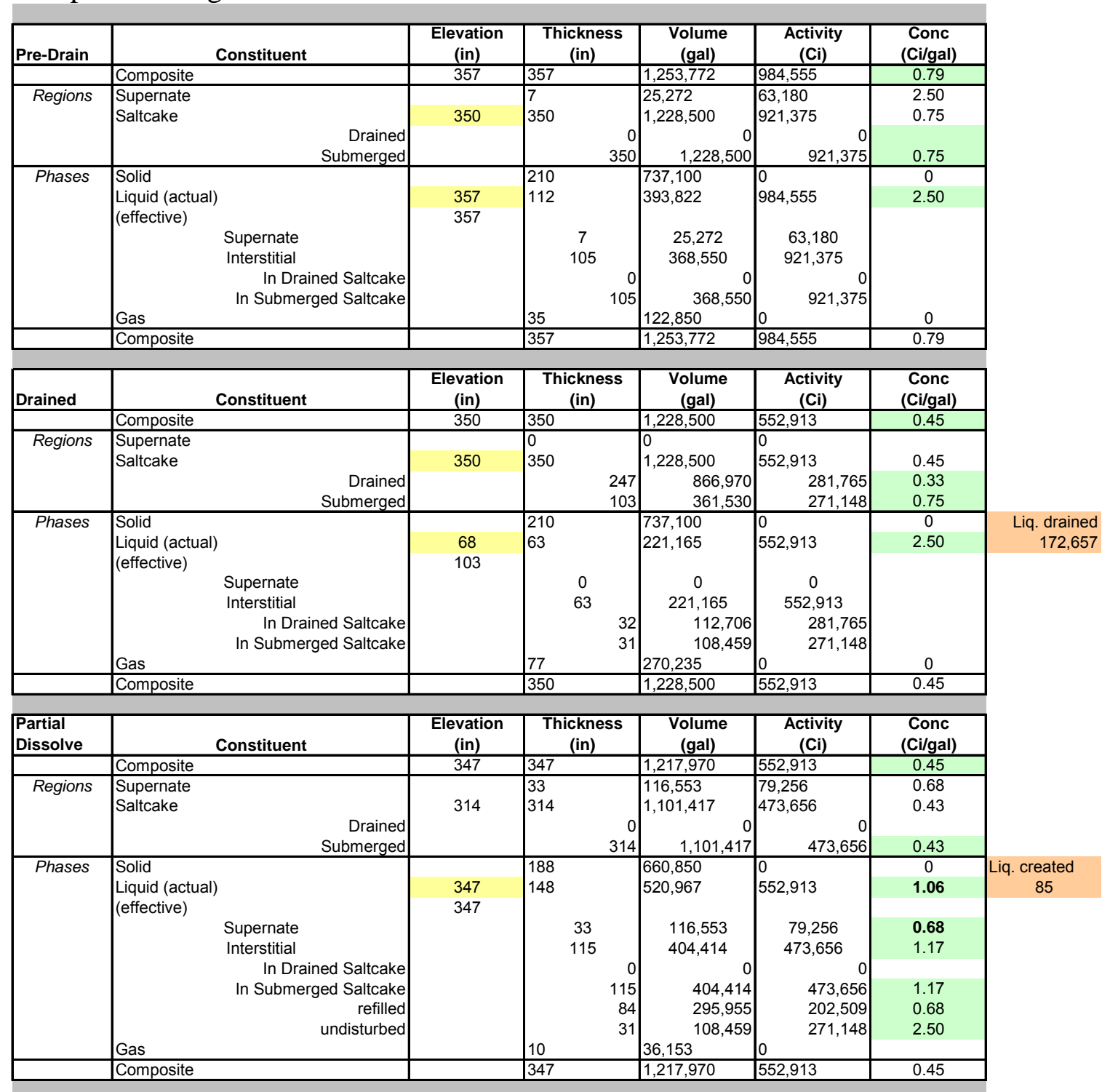

shading = key inputs shading = key outputs shading = auxiliary results 


\section{Appendix B - Estimation of Tank 41 and Tank 3 interstitial fluid properties as a function of temperature}

Dan McCabe (SRTC) estimated the properties of interstitial fluids in Tanks 41 and 3 using the OLI StreamAnalyzer. Software output for the analyses follows:

Tank 41 summary

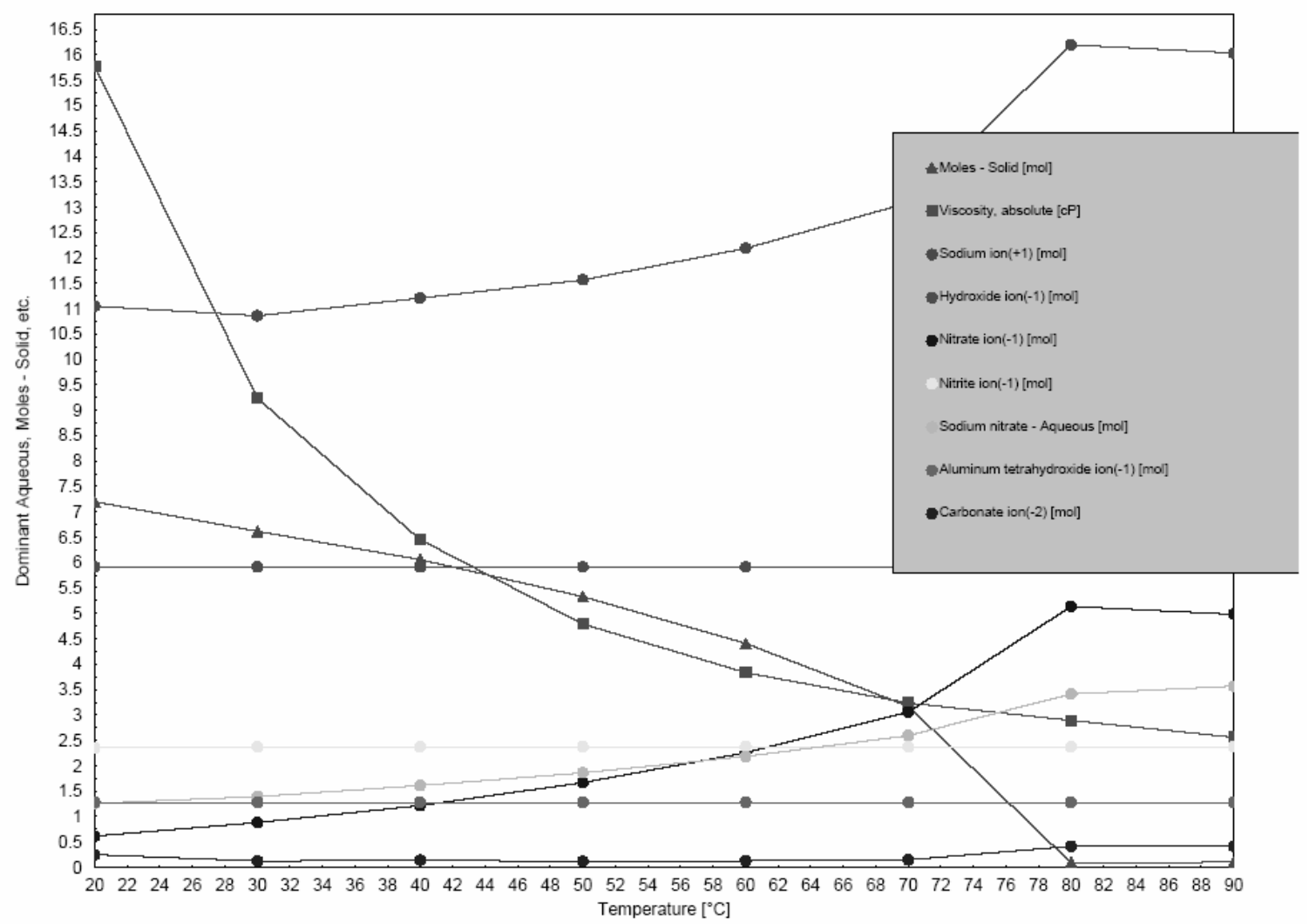




\section{Tank 3 summary}

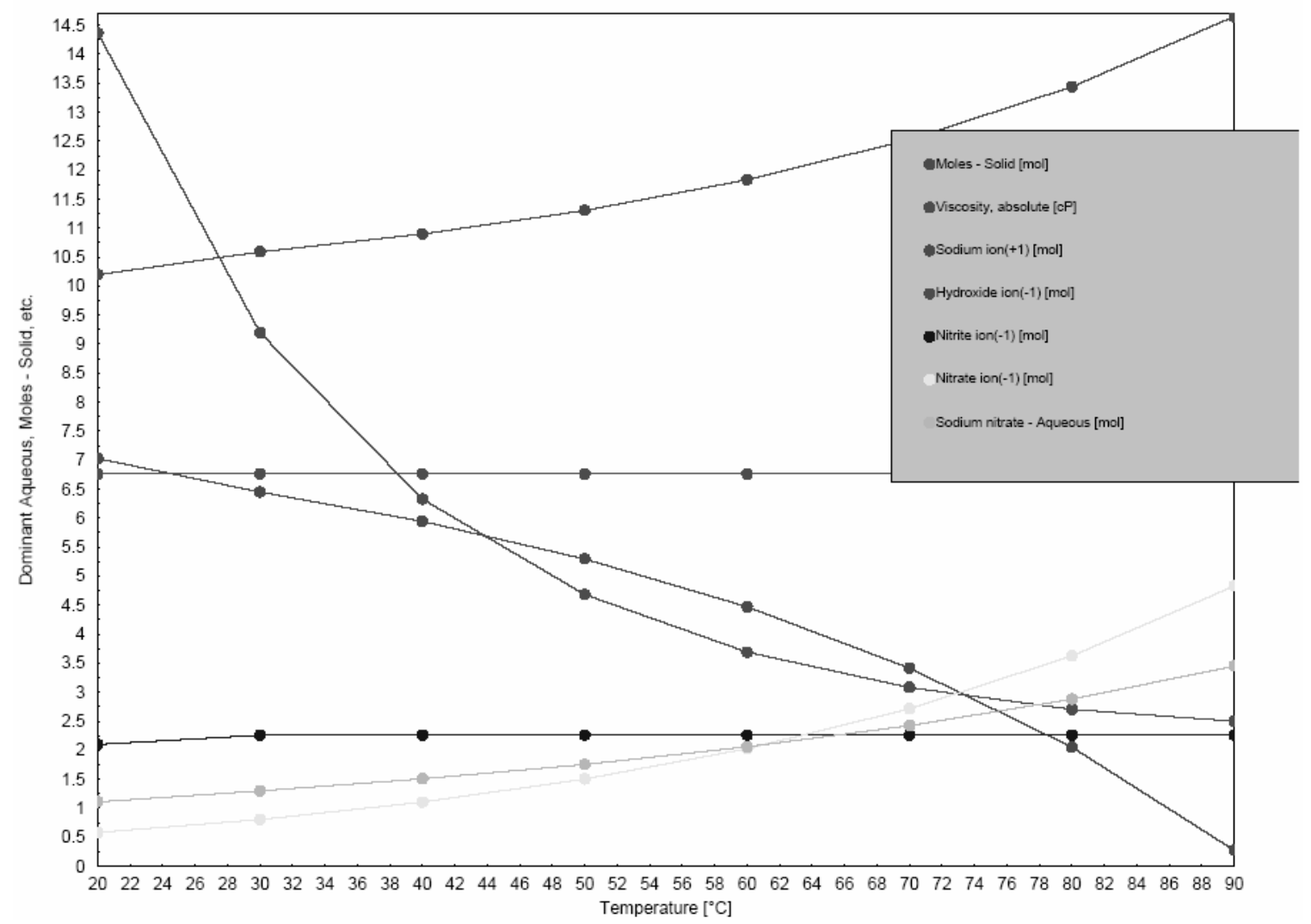




\section{Tank 41 details}

\section{Calculation Summary}

Survey3 Calculation for Work1

Automatic Chemistry Model

Databanks:

Public

Unit Set: Default

Temperature survey:

Range $\quad 20.000$ to $90.000^{\circ} \mathrm{C}$

Step size $10.000^{\circ} \mathrm{C}$

No. steps 7

No. points 8

No secondary survey selected

Isothermal Calculation

Calc. elapsed time: $20.625 \mathrm{sec}$

\section{Stream Inflows}

$\begin{array}{lll}\text { Water } & 42.000 & \mathrm{~mol} \\ \text { Sodium hydroxide } & 5.9100 & \mathrm{~mol} \\ \text { Sodium sulfate } & 0.59200 & \mathrm{~mol} \\ \text { Sodium chloride } & 0.12000 & \mathrm{~mol} \\ \text { Sodium fluoride } & 0.12000 & \mathrm{~mol} \\ \text { Sodium carbonate } & 0.43000 & \mathrm{~mol} \\ \text { Sodium nitrite } & 2.3700 & \mathrm{~mol} \\ \text { Sodium nitrate } & 8.5500 & \mathrm{~mol} \\ \text { Nitrogen } & 0.010000 & \mathrm{~mol} \\ \text { Sodium aluminate } & 1.2800 & \mathrm{~mol}\end{array}$




\section{Tank 3 details}

Calculation Summary

Survey5 Calculation for Work1

Automatic Chemistry Model

Databanks:

Public

Unit Set: Default

Temperature survey:

Range $\quad 20.000$ to $90.000^{\circ} \mathrm{C}$

Step size $\quad 10.000^{\circ} \mathrm{C}$

No. steps 7

No. points 8

No secondary survey selected

Isothermal Calculation

Calc. elapsed time: $5.047 \mathrm{sec}$

\section{Stream Inflows}

$\begin{array}{lll}\text { Water } & 42.000 & \mathrm{~mol} \\ \text { Sodium hydroxide } & 6.7600 & \mathrm{~mol} \\ \text { Sodium sulfate } & 0.0 & \mathrm{~mol} \\ \text { Sodium chloride } & 0.0 & \mathrm{~mol} \\ \text { Sodium fluoride } & 0.0 & \mathrm{~mol} \\ \text { Sodium carbonate } & 0.085000 & \mathrm{~mol} \\ \text { Sodium nitrite } & 2.2600 & \mathrm{~mol} \\ \text { Sodium nitrate } & 8.5500 & \mathrm{~mol} \\ \text { Nitrogen } & 0.010000 & \mathrm{~mol} \\ \text { Sodium aluminate } & 0.630000 & \mathrm{~mol}\end{array}$


This page intentionally left blank 